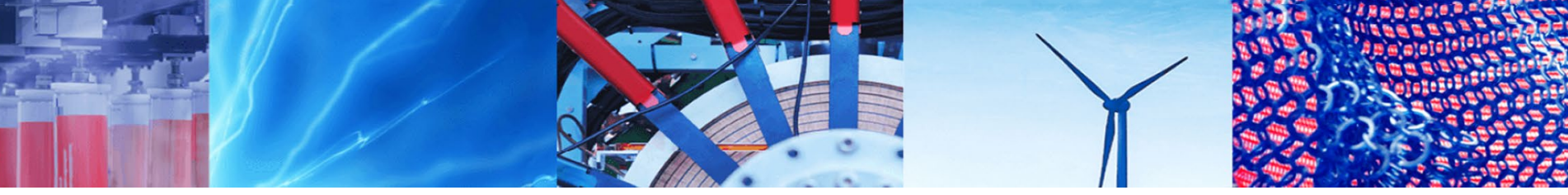

Research Article

\title{
Suitability of natural rocks as materials for cutting tools
}

\author{
Berend Denkena ${ }^{1} \cdot$ Bernd Breidenstein $^{1} \cdot$ Alexander Krödel $^{1}$ - Benjamin Bergmann ${ }^{1} \cdot$ Tobias Picker $^{1}$. \\ Philipp Wolters ${ }^{1}$ D
}

Received: 6 September 2021 / Accepted: 19 November 2021

Published online: 04 December 2021

(c) The Author(s) 2021 OPEN

\section{Article highlights}

- Demonstrating the possibility to use natural rocks as alternative environmentally friendly cutting toolmaterial.
- Evaluation of operational behaviour and wear mechanisms of rock tools in turning aluminium.

- Identification of rock properties relevant for the operational behaviour of rock inserts.

Keywords Natural rocks · Cutting tool materials · Grinding $\cdot$ Turning $\cdot$ Indexable inserts

\section{Introduction}

Modern manufacturing processes place high demands on cutting tool materials. Therefore, a constant improvement and redevelopment of these materials is needed to meet their demands. A disadvantage of modern high-performance cutting tool materials such as cemented carbides or polycrystalline diamond (PCD) is that they require rare materials and large amounts of energy for their production [1]. In addition, the partially critical availability of raw materials such as tungsten or cobalt poses a further challenge. Due to this and the high price of such materials, there is a high need to recycle and substitute them. This is especially true for regions where cutting tools are produced but where the raw materials are not mined like the USA [2] or the European Union [3, 4]. Therefore, research projects aim to find ways to substitute these critical raw materials [5] or to identify suitable alternative cutting tool materials [6]. In order to meet these challenges a cutting tool material with a high (global) availability, a low energy consumption in the production process and low raw material prices is required. Natural rocks could pose such an alternative. Rocks have a high global availability due to a large number of comparatively easily accessible deposits all over the world. In addition, the use of rocks means that complex und energy-intensive preparation and production processes for the cutting material can be dispensed with, as the cutting material rock is already available in nature in the required state. Compared to the production of a kilogram of conventional cemented carbide, for example, this would save between 290 and $480 \mathrm{MJ}$-equivalents of energy. In addition, this would also mean a reduction in emissions of climate affecting gases in the order of 10 to $19 \mathrm{~kg} \mathrm{CO}$-equivalents [1]. Overall, the use of rock as a cutting material could therefore provide the tool industry with a cost-effective alternative with high availability and a low energy demand in production compared to conventional cutting materials. At the same time, this would support the industry's shift towards greater sustainability, which is necessary with regard to climate change. So far, however, no systematic investigation of the usability and suitability of natural rocks as cutting tool materials has been carried out.

Philipp Wolters, wolters@ifw.uni-hannover.de | ${ }^{1}$ Institute of Production Engineering and Machine Tools (IFW), Leibniz University Hannover, An der Universität 2, 30823 Garbsen, Germany.

SN Applied Sciences $\quad$ (2022) 4:2 | https://doi.org/10.1007/s42452-021-04883-z 


\subsection{State of the art}

Previous performance improvements in cutting processes have been closely linked to new development and improvement of cutting tool materials. An ideal cutting tool material has a high hardness and toughness to enable cutting of the workpiece material and to withstand the loads of the cutting process. An ideal cutting material does not exist, because a high hardness and a high toughness in a material are incompatible $[7,8]$.

The properties of natural rocks are defined by the chemical and structural composition of the minerals and their proportions and distribution in the rock. Structure and composition are primarily influenced by the formation process of a rock. Therefore, the formation process is used to classify rocks [9]. Three rock classes are distinguished: igneous, sedimentary and metamorphic rocks. Igneous rocks are formed by the solidification of molten rocks or minerals. Sedimentary rocks are formed by a sedimentation of pieces of other rocks or by a chemical precipitation from a solution. Metamorphic rocks are formed by high pressure and temperature from rocks of the other groups. The properties of the rock are also influenced by the minerals it contains, the grain size, grain shape and a possible texture of the rock structure $[9,10]$. The grain size of rocks is often $0.2-2 \mathrm{~mm}$, which means three to four orders of magnitude larger than that of technically produced ceramics or cemented carbides [11]. Furthermore, the mechanical resilience of rocks is also influenced by structural defects like cracks or pores [9].

There are many different approaches to describe and investigate the properties of rocks. Indentation tests, for example, represent a method that can be used for the investigation of rock hardness. In this method an indenter is forced into the rock surface under controlled conditions. The resulting indentation can then be measured and related to hardness indices. Furthermore, it is possible to correlate the results of this method with other rock properties, e.g., the uniaxial compressive strength [12]. The application of mineralogical hardness scales (e.g., Mohs's and Rosiwal's hardness) or the application of dynamic or rebound tests (e.g., shore scleroscope test) [13] represent further methods for determining the hardness of rocks. However, though there are suggestions for standardised methods for rock characterisation e.g., by the international society for rock mechanics [14], a wide range of methods and indices is used in the scientific community for this purpose. For example, Meng identifies 80 different indices in the literature which are used to describe the brittleness of rocks. Meng further concludes that indices developed in one field are not necessarily applicable in other fields [15]. Therefore, it is currently unknown which test methods are suitable for determining the properties of rocks to be investigated with regard to their suitability for use as cutting tool materials. The fact that it is currently not known which rock properties are important for suitability as cutting tool materials also contributes to this.

There have also already been systematic investigations with regard to the fundamentals of material removal mechanisms in rock processing. Nishimatsu investigated the mechanics of rock cutting and developed a model for the calculation of the cutting force in these processes [16]. Further investigations enhanced the understanding of the relationship between the process parameters, the cutting forces, specific energy and specific cutting energy in rock machining [17] and contributed to the development of cutting parameter models e.g. for the machining of marble [18]. Garner found that it is possible to realise ductile material separation in rock processing in addition to brittle material separation. Garner identified the stresses at the cutting edge as the decisive factor for the occurring material removal mechanism [19]. This is an important finding for tool grinding, as brittle material removal can be a disadvantage in tool manufacture, e.g., if a low cutting-edge roughness is to be achieved during tool grinding. Further research extended the understanding of the principles of rock cutting by studying the material removal in different types of rock, as shown for example by Wang for marble [20]. Studies that provide a better understanding of the cause of the material removal mechanisms, their transition into each other and the tool - rock interaction also contribute to this, as shown e.g., by Huang [21]. The use of simulation approaches such as the finite element method (FEM) or the bonded particle method (BPM) is another way of investigating the complex processes involved in the cutting of rocks, as shown for example by Mohammadnejad [22].

Despite the advances in the field of basic knowledge of material removal mechanisms in rock machining and a wide range of work on this subject offered by the literature, it is not yet known to what extent this knowledge can be transferred to the manufacture of cutting tools made of rocks. One reason for this is that typical tool grinding processes such as plunge face grinding of indexable inserts have not been investigated so far for rocks. Therefore, it is also not known to what extent previous findings can be transferred to these processes. Furthermore, it has not yet been investigated how the material removal mechanisms that occur during the manufacture of rock tools influence the manufacture and operational behaviour of these tools. Another reason is that it is not yet known which rocks are suitable for tool production and for what reasons. It is of particular importance that different rocks can differ significantly from each other in many properties. Since these properties can be described in many different ways, as 
described above, and this characterisation can be application specific, it is not known whether previous models can be transferred to this new application.

Research that deals with the machining and processing of rocks away from basic research is often concerned in the engineering sciences with issues from civil engineering or mining. Examples for this are forecasts of rock mass strength in tunnelling projects [23] or the modelling of rock blasting processes [24]. Research topics in this field associated with production engineering often deal with the development and operational behaviour of tools for rock cutting like cutting discs [25, 26], gang saws [27] or wire sawing tools [28] as well as with the associated process design [29]. In addition, investigations in this field often aim to improve the understanding of the rock cutting processes and to optimise them, e.g., by better understanding the relationship of cutting force and chip thickness [30]. However, these investigations are mainly concerned with cutting rocks rather than making cutting tools from them. Therefore, in this field, too, there are no systematically reviewed findings on the manufacture and operational behaviour of cutting tools made of rocks or on the transferability of previous findings on the cutting processes of rocks to these issues.

Due to the previously mentioned gaps in the state of the art regarding the manufacture and operational behaviour of cutting tools made of rocks, this paper therefore aims to make contribution to closing these gaps. For this purpose, this paper investigates whether it is generally possible to manufacture indexable inserts from natural rocks which can be used in a cutting process. To this end, the mechanical properties of different rocks as well as the manufacturability of indexable inserts from these rocks via a plunge face grinding process are analysed. In addition, the operational behaviour of the manufactured inserts is tested and compared with conventional cemented carbide inserts in order to enable an initial assessment of the suitability of rocks as cutting tool materials. Therefore, the paper is organised as follows: After the description of the used materials and methods in Sect. 2, the results of the investigation are presented in Sect. 3 starting with the characterization of the rock properties in Sect. 3.1. Besides an analysis of mineral composition, grain size and microstructure the hardness and critical bending strength as well as correlations between these factors are investigated. Subsequently, the manufacture of the rock inserts via a plunge face grinding process and the resulting roughness of the flank faces and cutting edges are analysed in Sect. 3.2. In Sect. 3.3 the operational behaviour of the inserts in turning aluminium is analysed which is described by the wear of the inserts as well as the achieved surface roughness in this study. Finally, all results are summarised in Sect. 4.

\section{List of symbols}

$a_{\text {ed }} \quad$ Depth of cut in dressing

$a_{p} \quad$ Depth of cut

b Width of a sample

$b_{y} \quad$ Width of the chamfered cutting edge

Bt Biotite

Cc Calcite

Chl Chlorites

Cpx Clinopyroxene

$d_{g} \quad$ Grain size

Ep Epidote

$f \quad$ Feed

$\mathrm{F}_{c} \quad$ Cutting force

$F_{f} \quad$ Feed force

$\mathrm{F}_{z} \quad$ Vertical force

Gt Garnet

h Height of a sample

$\mathrm{H}$ Hardness

$\mathrm{I}_{\mathrm{cf}}$ Interlocking class factor

$I_{y y} \quad$ Area moment of inertia

Kfs K-feldspar

I Distance between the bearings in a 3-pointbending-test

$I_{c} \quad$ Cutting length

Ms Muscovite

Ol Olivine

Opx Orthopyroxene

Ox Oxides

PI Plagioclase feldspar

Qz Quartz

$\mathrm{r}_{\varepsilon} \quad$ Corner radius

$\mathrm{Ra}$ Arithmetic average of absolute roughness values

$\mathrm{Rz} \quad$ Mean roughness depth

$S \quad$ Average cutting-edge rounding

$\mathrm{S}_{a} \quad$ Cutting edge segment on flank face

$\mathrm{S}_{\gamma} \quad$ Cutting edge segment on rake face

$v_{c} \quad$ Cutting speed

$v_{f} \quad$ Feed velocity

$a_{c} \quad$ Clearance angle

$a_{c, p} \quad$ Clearance angle in the turning process

$\sigma_{c} \quad$ Critical bending strength

\section{Materials and methods}

\subsection{Rocks}

Eight different rocks and two mono minerals are used in this study. At least one rock of each general rock class is used in the investigations (see Table 1 ). In addition, the suitability of the minerals quartz and garnet as cutting tool materials is also investigated in this study. Before cutting, 
Table 1 Rocks used in the investigations

\begin{tabular}{lll}
\hline Igneous rock & Sedimentary rock & Metamorphic rock \\
\hline basalt & flint & Alta quartzite \\
lamellar obsidian & & Brazil quartzite \\
porphyry & & Silver quartzite \\
& & Wine Red quartzite \\
\hline
\end{tabular}

the raw rocks are available in various shapes, from blocks and nodules with lengths of up to $100 \mathrm{~mm}$ to slabs up to $22 \mathrm{~mm}$ thick.

For the cutting of the rock samples from the raw rocks for the grinding tests, a DEMA WB 2000 rock saw and a Struers Discotom-10 cut-off grinding machine are used. Square samples with dimensions $20 \times 20 \mathrm{~mm}$ are made. Rock samples with a pronounced texture are cut in such a way that the texture is aligned in two different ways to investigate the influence of the texture on the grinding process and the operational behaviour of the indexable inserts. As shown in Fig. 1, in the first case the texture is aligned parallel to the rake face and thus perpendicular to the cutting force $F_{c}$ in the turning process. In the second case texture is aligned perpendicular to the rake face and thus in the direction of the cutting force. To indicate the alignment of the samples every sample with a texture alignment parallel to the rake face (perpendicular to the cutting force in turning) is marked with (X) behind the sample name. Samples with a texture aligned parallel to the cutting force in turning are marked with ( ||$)$ behind the sample name.

\subsection{Thin sections and X-ray diffraction}

Thin section microscopy and X-ray diffraction are used to analyse composition, grain size of the minerals, occurring textures, cracks in the fabric and mineral alterations of the samples. The thin section samples are cut with a Struers Discoplan-PS saw into rectangles measuring $3.5 \times 2 \mathrm{~cm}$. A diamond grinding tool with a grain size of $76 \mu \mathrm{m}$ (D76) is used for the grinding of the samples.
The polishing of the samples is done manually with four silicon carbide grinding powders with grain sizes of 201, 68, 30.2 and $18.3 \mu \mathrm{m}$ (P80, P220, P500 and P1000). The thin sections have a thickness of $25 \mu \mathrm{m}$. A Leitz DMPR microscope equipped with a Leica DFC295 camera is used for the analysis of the thin sections. The examination of the phase composition of the rocks is carried out with a Bruker D4 Endeavor powder diffractometer. The measurements are done with a copper anode in theta/2 theta mode with a step size of $2 \theta=0.02^{\circ}$ using a start position of $2 \theta=5^{\circ}$ and an end position of $2 \theta=80^{\circ}$. The composition is determined with the software Powder Cell which is based on the Rietveld-refinement [31] for the quantitative determination of crystallographic components of powder samples.

\subsection{Hardness measurement}

Since hardness is an important property of rocks in order to assess their suitability as cutting materials, a Struers Duramin hardness tester and an Agilent Technology G200 Nanoindeter are used for hardness measurements. The Sturers Duramin hardness tester is used to perform Vickers hardness tests (HV0.3) according to DIN EN ISO 6507-2 [32] and DIN EN 843-4 [33]. For the nanoindentation a Berkovich tip and an indentation depth of $2000 \mathrm{~nm}$ was used. Ten indentations are made for each sample for the Vickers hardness tests and 49 for the nanoindentation tests. It should be noted, that a high standard deviation of the results is expected due to the possibility to hit different mineral grains with different hardness. This is a possible error source which cannot be neglected in the analysis of the results.

\subsection{Critical bending strength}

The critical bending strength of the rocks is determined by fracture tests. The determination of the critical bending strength is based on DIN EN 843-1 [34], which specifies the determinations of the bending strength of monolithic ceramics. It must be borne in mind, however, that the specifications of the standard with regard to ceramics
Fig. 1 Alignment of textures in the rock samples in relation to the direction of cutting force, using the example of Alta quartzite

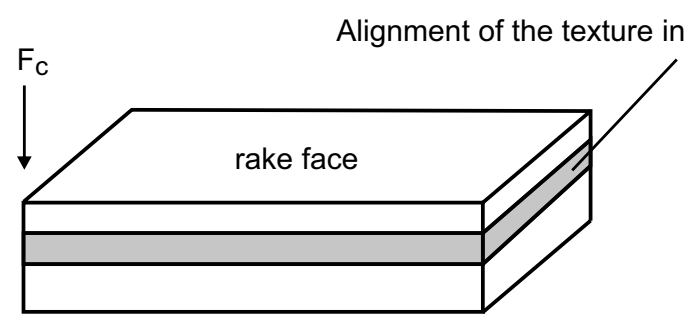

Alta quartzite (X)

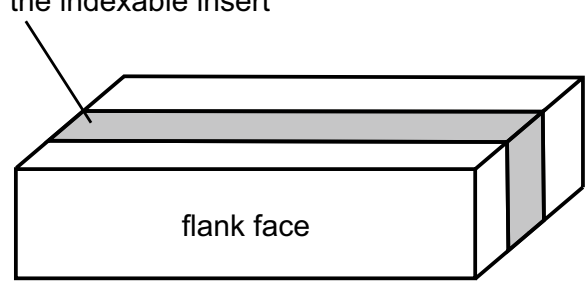

Alta quartzite (II) 
Table 2 Average surface roughness of the ten samples for the testing of critical bending strength

\begin{tabular}{llr}
\hline Rock & $\mathrm{Ra}(\mu \mathrm{m})$ & \multicolumn{1}{c}{$\mathrm{Rz}(\mu \mathrm{m})$} \\
\hline Alta quartzite & $0.88 \pm 0.13$ & $7.82 \pm 1.73$ \\
basalt & $1.09 \pm 0.43$ & $9.65 \pm 2.99$ \\
Brazil quartzite & $2.55 \pm 0.46$ & $18.62 \pm 2.20$ \\
flint & $0.20 \pm 0.04$ & $2.06 \pm 0.41$ \\
garnet & $3.58 \pm 0.88$ & $24.21 \pm 3.89$ \\
lamellar obsidian & $0.26 \pm 0.11$ & $2.71 \pm 0.92$ \\
porphyry & $1.54 \pm 0.45$ & $10.87 \pm 3.52$ \\
quartz & $0.32 \pm 0.06$ & $3.70 \pm 0.72$ \\
Silver quartzite & $1.52 \pm 0.36$ & $12.69 \pm 2.58$ \\
Wine Red quartzite & $2.20 \pm 0.28$ & $14.64 \pm 1.63$ \\
\hline
\end{tabular}

cannot be fully transferred to rocks. Ten samples are tested for each rock. The samples are loaded with a vertical force $F_{z}$ in a three-point-bending-test. The force is measured with a Kistler dynamometer 9257B. The critical bending stress $\sigma_{c}$ can be calculated using the width $b$ of $20 \mathrm{~mm}$ and the height $h$ of $5 \mathrm{~mm}$ of the samples and the distance I of $13 \mathrm{~mm}$ between the bearings of the bending test. Apart from cutting the samples into these shapes, taking into account potential texture alignment, no further preparations are made to the samples. Although this leads to different roughness values of the rocks, which can affect their bending strength, this is also the condition in which the samples are used in the grinding experiments. Average roughness values of the samples after cutting and before the bending tests are given in Table 2 including standard deviations. With the assumption that the area moment of inertia $\mathrm{I}_{\mathrm{yy}}$ can be calculated with

$I_{y y}=\frac{b \cdot h^{3}}{12}$

the critical bending strength can be calculated using the following equation

$\sigma_{c}=\frac{3 \cdot F_{z} \cdot 1}{2 \cdot b \cdot h^{2}}$

\subsection{Grinding experiments}

All grinding experiments were conducted as a plunge face grinding operation on a cutting insert grinding machine Wendt WAC 715 Centro. During grinding of the flank faces of the indexable inserts the grinding tool oscillated transversely to the cutting direction (orthogonal to $v_{f}$ and $v_{c}$ ) with an oscillation frequency $f_{o z}$ of two Hertz. The parameter settings of the grinding experiments are summarized in Table 3.
Table 3 Parameter settings of the grinding experiments

\begin{tabular}{lll}
\hline Process variables & Unit & \\
\hline Cutting speed $\mathrm{v}_{\mathrm{c}}$ & {$[\mathrm{m} / \mathrm{s}]$} & 30 \\
Feed velocity $\mathrm{v}_{\mathrm{f}}$ & {$[\mathrm{mm} / \mathrm{min}]$} & 4 \\
Oscillating frequency $\mathrm{f}_{\mathrm{oz}}$ & {$[\mathrm{Hz}]$} & 2 \\
Cooling lubricant & {$[-]$} & oil \\
\hline
\end{tabular}

Table 4 Parameter settings of the turning experiments

\begin{tabular}{llll}
\hline Process variables & Unit & Levels & \\
\hline Depth of cut $\mathrm{a}_{\mathrm{p}}$ & {$[\mathrm{mm}]$} & 0.5 & 1 \\
Feed $\mathrm{f}$ & {$[\mathrm{mm}]$} & 0.05 & 0.1 \\
Cutting speed $\mathrm{v}_{\mathrm{c}}$ & {$[\mathrm{m} / \mathrm{min}]$} & 600 & \\
Cutting length $\mathrm{I}_{\mathrm{c}}$ & {$[\mathrm{m}]$} & 500 & \\
\hline
\end{tabular}

The cooling lubricant used is a low-viscosity mineral oil (R-Oil HM7, Rhenus), which is induced into the process via a cylindrical nozzle. For all grinding experiments, a cup grinding wheel with a diameter of $400 \mathrm{~mm}$ and a width of the abrasive layer of $15 \mathrm{~mm}$ is used. The grinding tool has a vitrified bond with diamond as abrasive, an abrasive grain size of $46 \mu \mathrm{m}$ (D46) and a grain concentration of C100. Profiling and sharpening of the grinding tool are performed in a single continuous process by a cup dressing roller of white corundum with a grain size of $\mathrm{d}_{\mathrm{g}}=125 \mu \mathrm{m}$ (ANSI \#120) and a vitrified bond. The dressing process is performed in counter direction parallel to the face of the dressing roller. The depth of cut in the dressing process is $\mathrm{a}_{\mathrm{ed}}=0.5 \mu \mathrm{m}$ per feed pulse and the cutting speed of the dressing process is $2 \mathrm{~m} / \mathrm{s}$. In the grinding process indexable inserts with a clearance angle $a_{c}$ of $3^{\circ}$ are manufactured for the turning experiments. All inserts have a corner radius $r_{\varepsilon}$ of $0.8 \mathrm{~mm}$ and a chamfered cutting edge with a width of $b_{\gamma}=200 \mu \mathrm{m}$. The surface roughness of the rock samples after the grinding process is measured optically with a Confovis DuoVario confocal microscope. For the analysis of the measurement data the software MountainsMap is used. The roughness of the cutting edge and the size of the cutting edge rounding after grinding are measured optically with an Alicona Infinite Focus G5 focus variation microscope. For the determination of the surface and cutting-edge roughness five samples each were measured. Furthermore, a Zeiss EVO 60 scanning electron microscope is used to investigate the surface of the indexable inserts after grinding.

\subsection{Turning experiments}

All turning experiments are conducted with a Gildemeister CTX 520 lathe and are repeated twice. The parameter 
settings are shown in Table 4. A CSSNL 2525M12 tool holder is used to fasten the indexable inserts in the lathe. The holder leads to an effective clearance angle $a_{c, p}$ of $15^{\circ}$ $\left(a_{c}=3^{\circ}\right)$ in the process. Cemented carbide indexable inserts (SNMA120408) are used as comparison cutting material in order to provide an indication of the performance of the indexable inserts made from rock. The composition is $94 \%$ tungsten carbide with $6 \%$ cobalt as binder phase, the average grain size of tungsten carbide is $0.6 \mu \mathrm{m}$ (hardness $1900 \mathrm{HV} 30$, fracture toughness $\mathrm{K}_{\mathrm{IC}}=9.0 \mathrm{MPa} \cdot \mathrm{m}^{1 / 2}$, flexural strength $=3,900 \mathrm{MPa}$ ). The cemented carbide inserts were coated with an $18 \mu \mathrm{m}$ thick TiCN coating using a CVD coating process. In all turning experiments aluminium cylinders (EN AW 2007-T4 with a tensile strength of $\mathrm{R}_{\mathrm{m}}=340 \mathrm{MPa}$, a yield strength of $\mathrm{R}_{\mathrm{p} 0.2}=200 \mathrm{MPa}$ and $\mathrm{a}$ thermal conductivity of $\lambda=145 \mathrm{~W} /(\mathrm{m} \cdot \mathrm{K}))$ with a diameter of $150 \mathrm{~mm}$ and a length of $200 \mathrm{~mm}$ are used as workpiece. The aluminium alloy contains the following mass frictions of additional elements according to DIN EN 573-3 [35]: 0.8 wt.\% Si, 0.8 wt.\% Fe, 3.3-4.6 wt.\% Cu, 0.5-1.0 wt.\% Mn, 0.4-1.8 wt.\% Mg, 0.1 wt.\% Cr, 0.2 wt.\% Ni, 0.8 wt.\% Zn, $0.2 \mathrm{wt} . \% \mathrm{Ti}$. The surface roughness of the workpiece after turning is measured tactilely with a Hommel etamic W5 roughness measuring instrument. Three measurements of surface roughness were taken for each experiment. Tool wear was inspected after a cutting length of $I_{c}=500 \mathrm{~m}$ by scanning electron microscopy (SEM) using a backscattered electrons detector. The records were taken with a Zeiss EVO 60 XVP (tungsten cathode) microscope. The process forces were measured using a Kistler three component dynamometer type 9121A. An analysis of the generated chips was carried out after grinding, polishing, and etching with $2 \%$ nitric acid using metallographic micrographs.

\section{Results and discussion}

\subsection{Characterisation of rock properties}

The mineral content and composition of the rock samples has an influence on the mechanical properties of the rocks. A high amount of soft minerals in the fabric of the rock e.g., leads to a low hardness and/or strength of the rock. Therefore, it is useful to know what minerals are contained in a rock to get a better understanding of its mechanical properties. The use of powder diffractometry allows to investigate the mineral content of the rock samples. The results of these investigations are shown in Table 5. It must be mentioned that due to the high number of minerals in the rocks only mineral phases with a volume proportion of at least one percent are considered. It is assumed that mineral phases with a lower volume proportion do not significantly influence the mechanical properties of the rocks. It was not possible
Table 5 Mineral stock of the rocks

\begin{tabular}{ll}
\hline Rock & Phase composition [Vol.\%] \\
\hline $\begin{array}{l}\text { Alta quartzite } \\
\text { basalt }\end{array}$ & Qz 76; Ms 15; Kfs 4; Ox 2; Chl 1; Ep 1 \\
Brazil quartzite & Qz 95; Ms 4; Ep 1 \\
flint & Qz 94; Cc 6 \\
garnet & Gt 84; Ep 6; Ox 6; Chl 4 \\
lamellar obsidian & - \\
porphyry & Qz 58; Kfs 16; Cc 14; Pl 5; Ox 3; Bt 2; Chl 2 \\
quartz & Qz 100 \\
Silver quartzite & Qz 96; Ms 2; Ep 1; Ox 1 \\
Wine Red quartzite & Qz 95; Kfs 3; Ep 2; Ms 1 \\
\hline
\end{tabular}

Bt: biotite; Cc: calcite; Chl: chlorites; Cpx: clinopyroxene; Ep: epidote; Gt: garnet; Kfs: K-feldspar; Ms: muscovite; Ol: olivine; Opx: orthopyroxene; Ox: oxides; PI: plagioclase feldspar; Qz: quartz

to determine the phase composition of the lamellar obsidian due to its amorphous structure. The analyses show that quartz has the highest volume proportion in most of the investigated rocks with the exceptions of basalt and garnet. It can also be seen that the quartzites differ in their mineral content and the volume proportion of the mineral phases. The Alta quartzite for example contains a relative low volume proportion of quartz for a rock classified and sold as quartzite. Furthermore, it contains the highest volume proportion of the comparably soft mineral muscovite.

Other factors which influence the mechanical properties of the rocks are size, shape and interlocking of the grains. Grain boundaries are insurmountable barriers for dislocations and influence therefore how easy a deformation of the material can take place. A finer grain size is often associated with a higher strength of the material [36]. Grain size can be determined by thin sections based on the intercept length of the grains. A grain size for lamellar obsidian, quartz and garnet cannot be given because they have either an amorphous structure or are single crystals. However, inclusions can be found in the garnet, whose size is given here. The average grain size of the rock samples is between 0.28 and $0.46 \mathrm{~mm}$ except for flint and the Wine Red quartzite which have an average grain size of $0.02 \mathrm{~mm}$ and $0.13 \mathrm{~mm}$. Compared to grain sizes for conventional cutting materials, such as cemented carbides $(0.1-10 \mu \mathrm{m})$ [37] these rocks have a high grain size, but compared to other rocks they are classified as very fine-grained (grain size between 0.2 and $0.5 \mathrm{~mm}$ ) or even extremely fine-grained (grain size $<0.2 \mathrm{~mm}$ ). Although the size of many grains in the microstructure is close to the given mean values, significantly larger grains are also found in the microstructures in most rocks. However, the distribution of grain sizes is comparable for all rocks except for flint and Wine Red quartzite as can be seen in Fig. 2. In 


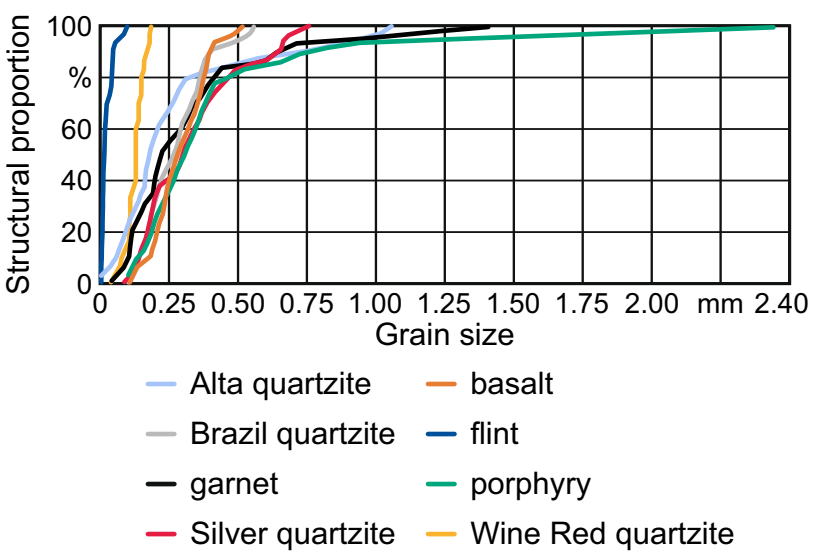

Fig. 2 Proportion of rock grains of different grain sizes in the microstructure

contrast to the rest of the rocks the grain size distribution of these two rocks is limited to a range of $0.007-0.100 \mathrm{~mm}$ (flint) and 0.06-0.18 mm (Wine Red quartzite), while for the other rocks this ranges from 0.05 to $2.30 \mathrm{~mm}$.

The interlocking of the microstructure also influences how easily the material can be deformed in a certain direction. The reason for this is that the structural cohesion of a rock is influenced by the grain surfaces in contact with each other in the microstructure and the resulting contact forces. The shape of the grains in rocks differs not only because of the preferred crystallographic shape of the minerals, but also because of the loads and chemical processes involved in the formation of the rocks. This leads, for example, to the formation of very different grain shapes in the quartzites. In order to make the interlocking of the microstructure comparable, the rocks are divided into three interlocking classes based on two classification criteria. The first criterion takes into account the shape of the grains as well as their interlocking visible in the thin sections. Allocation to the interlocking classes based on this criterion is carried out according to the following principles: The first interlocking class consists of all rocks without grain boundaries or with very round grains with only few or no edges at the grains which can interlock. The second consists of all rocks that have an angular grain shape with irregular grain boundaries that make it difficult for the grains to slide past each other under load. The third consists of all rocks with highly irregular angular grain shapes and clearly interlocked grain boundaries.

The second criterion aims on quantifying the grade of interlocking. It can be assumed that the length of the grain boundaries of two grains of comparable size will be very different if one of the grains is very round and the other has many corners and dimples that can interlock with other grains. It can also be assumed that in the second case the grain has a longer grain boundary and a higher ability to interlock with other grains. Based on the hypothesis that the ability of a grain to interlock with other grains can be described as a function of its size with the help of the length of its grain boundaries, a classification criterion can therefore be determined with these two variables. Therefore, the image processing software ImageJ is used to evaluate the length of grain boundaries of single grains. A dimensionless parameter $I_{\text {cf }}$ is then formed from the mean length of the grain boundaries of the individual grains by dividing this by the average grain size of the respective rock. This interlocking class factor $\mathrm{I}_{\mathrm{cf}}$ can then be used to quantify the grade of interlocking in the microstructure and to assign the rocks to the interlocking classes.

Hence, all rocks with an $\mathrm{I}_{\mathrm{cf}}<1.5$ are assigned to the first interlocking class. Rocks with an $I_{\text {cf }}$ between 1.5 and 4.5 are assigned to the second interlocking class and those with an $\mathrm{I}_{\mathrm{cf}}>4.5$ are assigned to the third class. For amorphous rocks like obsidian or single crystals it is not possible to calculate an $\mathrm{I}_{\mathrm{cf}}$. Because of that, they are assigned to the interlocking classes solely on basis of the first criterion. In addition, it is suggested that the first criterion should always be used first to check the general assignability to an interlocking class and then the second criterion $\left(\mathrm{I}_{\mathrm{cf}}\right)$ should be used to check the assignment. Examples for the interlocking classes are shown in Fig. 3 by thin sections. The
Interlocking class I

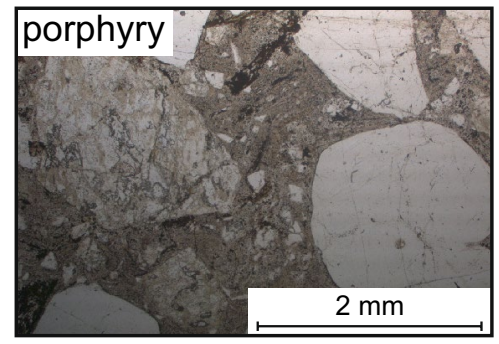

Low grade of interlocking
Interlocking class II

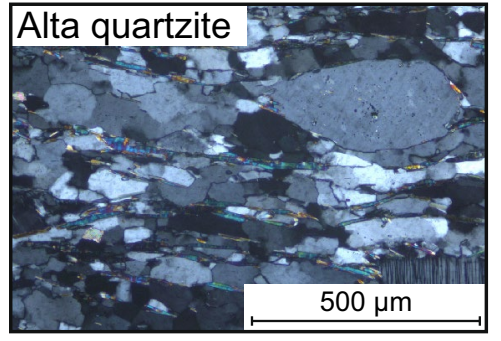

Average grade of interlocking
Interlocking class III

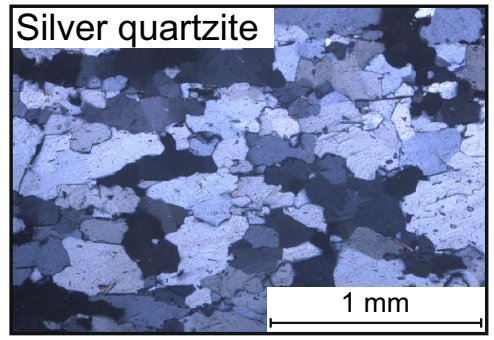

High grade of interlocking

Fig. 3 Examples for the three interlocking classes used in this investigation shown using thin sections 
Table 6 Classification of the interlocking class of the rocks beside their respective interlocking class factor

\begin{tabular}{llll}
\hline $\begin{array}{l}\text { Interlocking } \\
\text { class }\end{array}$ & $\begin{array}{l}\text { I (low grade of inter- } \\
\left.\text { locking, } I_{\mathrm{cf}}<1.5\right)\end{array}$ & $\begin{array}{l}\text { II (average grade of interlocking, } \\
\left.1.5 \leq \mathrm{I}_{\mathrm{cf}} \leq 4.5\right)\end{array}$ & $\begin{array}{l}\text { III (high grade of inter- } \\
\left.\text { locking, } \mathrm{I}_{\mathrm{cf}}>4.5\right)\end{array}$ \\
\hline & garnet $\left(\mathrm{I}_{\mathrm{cf}}=1.4\right)$ & Alta quartzite $\left(\mathrm{I}_{\mathrm{cf}}=1.8\right)$ & Brazil quartzite $\left(\mathrm{I}_{\mathrm{cf}}=5.8\right)$ \\
& lamellar obsidian & basalt $\left(\mathrm{I}_{\mathrm{cf}}=2.1\right)$ & Silver quartzite $\left(\mathrm{I}_{\mathrm{cf}}=4.8\right)$ \\
& porphyry $\left(\mathrm{I}_{\mathrm{cf}}=1.3\right)$ & flint $\left(\mathrm{I}_{\mathrm{cf}}=3.3\right)$ & \\
& quartz & Wine Red quartzite $\left(\mathrm{I}_{\mathrm{cf}}=2.8\right)$ & \\
\hline
\end{tabular}

classification of the rock samples according to the interlocking classes are shown in Table 6 besides their respective $\mathrm{I}_{\mathrm{cf}}$.

Other factors that can influence the mechanical properties of the rocks are textures and crack systems. A texturing of the microstructure of the rocks leads to an anisotropic mechanical behaviour. This is particularly important for the manufacture and use of tools made of rocks when the forces acting in the cutting or manufacturing process are in a direction where, for example, its hardness or critical bending strength is lower due to texturing. An example of this are layers of elongated soft muscovite grains, which could easily split under shear stress (intragranular separation) or separate from the surrounding microstructure and thus lead to a failure of the structure. Five of the examined rocks show a texturing of the microstructure. Besides the four quartzites, the lamellar obsidian also shows a chemical texturing in the form of lamellae. It is therefore assumed that the influence of the texture on the mechanical properties is small in this case. Examples for the textures in the rock samples are given in Fig. 4.

The rocks are divided into two classes according to their texture, depending on whether isotropic or anisotropic material properties can be expected. Rock samples with an isotropic texture (texture class I) show a directionless granular microstructure in the thin sections. Rock samples with an anisotropic texture (texture class II) show a preferred grain shape orientation in the thin sections. The assignment of the rocks to these two classes is shown in Table 7.
Cracks represent potential weak points in the microstructure, especially under mechanical stress. The propagation of existing cracks makes it easier for the material to fail, particularly in the case of tensile stresses. The material can then already fail below its usual tensile strength due to crack propagation. Examples for cracks in the microstructure are shown in Fig. 5. High crack densities are especially found in thin section analysis in minerals with a high cleavability like feldspar or muscovite while minerals with a low cleavability like quartz show a lower crack density. An exception from this is garnet which shows the most cracks in the comparison of the rock samples. The micaceous samples show a parallel orientation of the cracks to the gap surfaces of the mica layers. Highly concentrated mica layers also show a higher crack density than those which are more dispersed in the sample. Due to this a correlation between the crack density of micaceous rocks, the volume share of mica and the degree of concentrated layer formation is possible.

In order to include crack density in a later evaluation of the suitability of the rock as a cutting material, the rocks are classified according to the crack characteristics present in the microstructure. The first crack class comprises rocks without or with only few cracks, which have no preferred orientation and are intragranular. The second crack class comprises rocks with a clearly recognizable number of cracks in their mineral phases, some of which may have a preferred orientation and exhibit an inter- to transgranular course. The third crack class comprises rocks with a high number of cracks in the
Fig. 4 Examples for isotropic and anisotropic textures of the rocks shown using thin sections

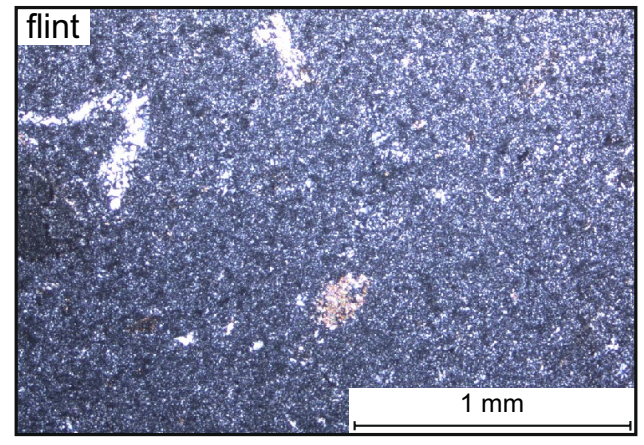

Isotropic texture

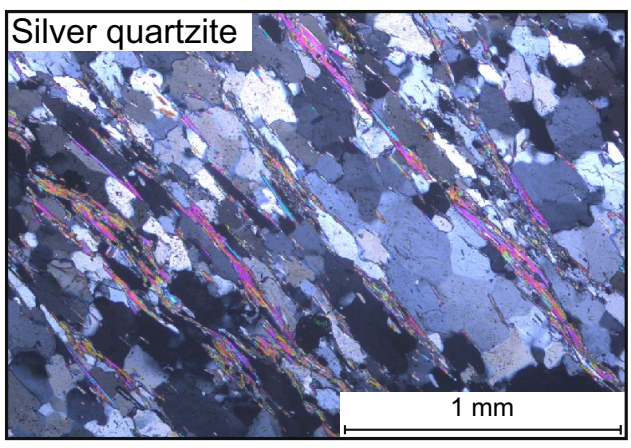

Anisotropic texture 
Table 7 Texture classes of the rock samples

\begin{tabular}{ll}
\hline Texture class I (isotropic) & Texture class II (anisotropic) \\
\hline basalt & Alta quartzite \\
flint & Brazil quartzite \\
garnet & lamellar obsidian \\
porphyry & Silver quartzite \\
quartz & Wine Red quartzite \\
\hline
\end{tabular}

microstructure and an increased tendency of the cracks to occur at the grain boundaries. The cracks in this class also have a pronounced intragranular orientation. The assignment of the rocks to the crack classes according to these terms are shown in Table 8.

As mentioned before the hardness of a cutting tool material has a significant influence on its operational behaviour and is therefore an important property. The results of the hardness measurements of the rock samples are shown in Fig. 6. Hardness is between 5.53 and $11.40 \mathrm{GPa}$ for the Vickers test and between 7.61 and $13.02 \mathrm{GPa}$ for the nanoindentation. Hardness measurement via nanoindentation could not be performed for garnet because no suitable samples for the indentation were available. The different scales on which these two methods operate could provide an explanation for the differences in the measured hardnesses. While nanoindentation is working on a nanoscale (indentation depth up to $2000 \mathrm{~nm}$ and indentation forces of up to $0.55 \mathrm{~N}$ in this case) the Vickers method acts on a microscale. It is well established that single crystal materials or bulk microcrystalline materials show a so called "indentation size effect". This means that the hardness of a material decreases with an increase of the sampling volume or respectively an increase of the
Fig. 5 Examples for cracks in the microstructure of the rocks shown using thin sections

Table 8 Crack classes of the rock samples
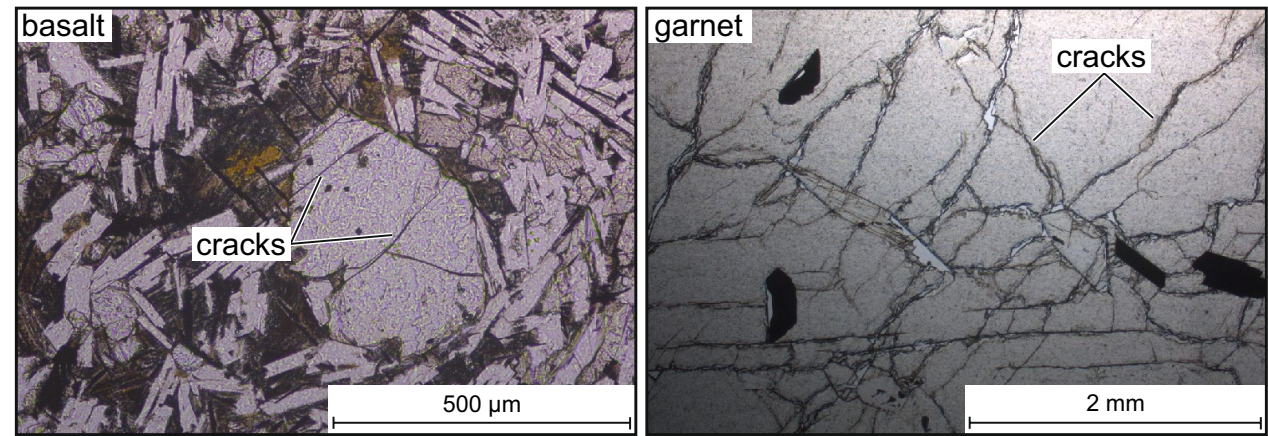

\begin{tabular}{llll}
\hline Crack class & I (low crack density) & II (average crack density) & III (high crack density) \\
\hline & flint & basalt & Alta quartzite \\
& lamellar obsidian & Silver quartzite & Brazil quartzite \\
porphyry & Wine Red quartzite & garnet \\
& quartz & & \\
\hline
\end{tabular}

Fig. 6 Hardness of the rocks determined with the help of Vickers hardness tests and nanoindentation

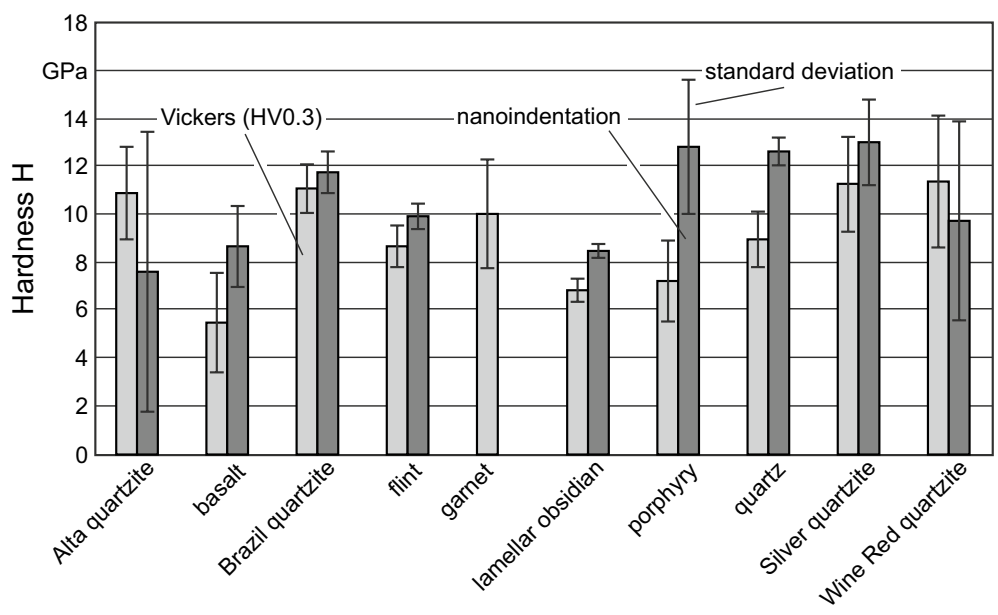

SN Applied Sciences A SPRINGER NATURE journa 
Fig. 7 Critical bending strength of the rocks determined using three-pointbending-tests

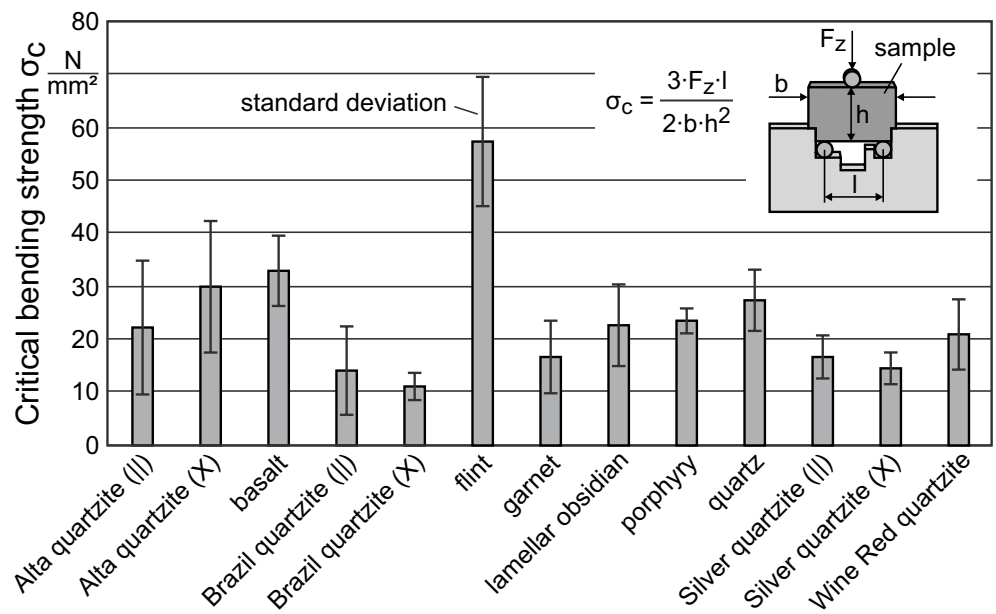

capacity of grinding wheel bonds [39]. An increased critical bending strength therefore also indicates an increased load-bearing capacity of the rock samples. Measurement results are shown in Fig. 7. The critical bending strength of the rock samples ranges between $11.09 \mathrm{MPa}$ (Brazil quartzite $(\mathrm{X})$ ) and $57.62 \mathrm{MPa}$ (flint).

Correlating hardness and critical bending strength with the characterisation classes defined before, it can be seen that texture, the interlocking of the grains and the cracks in the fabric influence hardness and critical bending strength. Rocks with a higher interlocking class tend to show a higher Vickers hardness, as can be seen in Fig. 8 .

This also means that this effect should show an anisotropic behaviour for fabrics in which the interlocking of the grains is aligned in only one direction. However, in all investigated rocks there is no preferred orientation of the interlocking in the fabric. Due to that it is assumed that the influence of the interlocking is isotropic. It must be mentioned that this effect could only be observed for the Vickers hardness. For nanoindentation measurements no influence of the interlocking could be observed. Considering that the interlocking parts of the grains in most cases are bigger than the indentation depth in nanoindentation, it can be assumed that the interlocking only influences macro hardness. Therefore, factors like mineral content and mineral hardness should have a greater influence on nanohardness.

The interlocking of the grains has the opposite influence on the critical bending strength that it has on hardness, but to a lesser extent. Rocks with a higher interlocking class tend to show lower critical bending strengths as can be seen in Fig. 9. While the interlocking of the grains can increase hardness as mentioned before it can act as a crack initiator and "splitting wedge" under loading, especially if a hard and a soft mineral are interlocked with very sharp edges. This would lower the load-bearing capacity of the material due to crack propagation and 


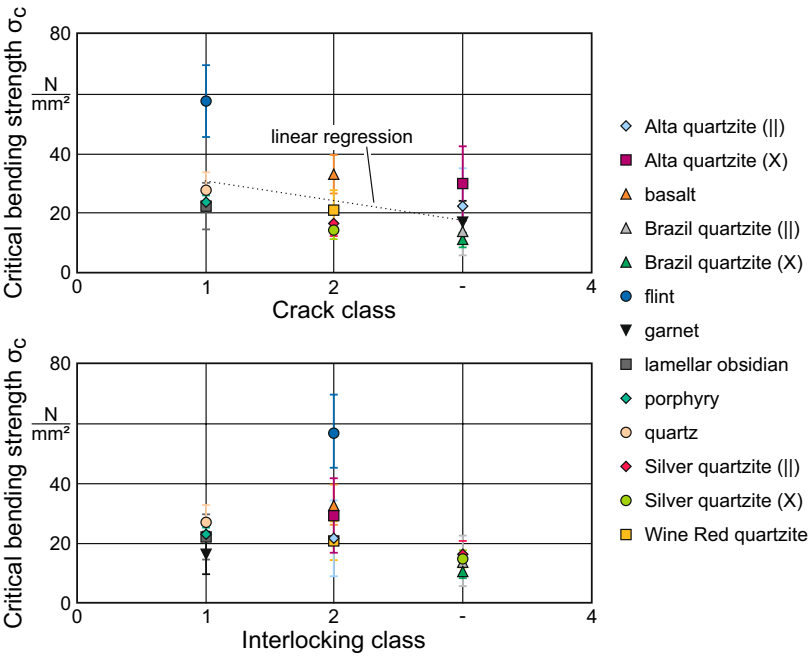

Fig. 9 Influence of crack and interlocking class on critical bending strength of the rocks

thus the critical bending strength. It can also be seen that rock samples classified in a higher crack class tend to show a lower critical bending strength. The reason for this is the higher number of cracks in the microstructure with an orientation which ease the crack propagation with a higher crack class. These cracks in the fabric are able to grow under the combined tensile/compressive loading of the three-point bending test. Crack growth ultimately leads to a failure of the material and thus limits its critical bending strength. Regarding texture no uniform influence on the critical bending strength can be determined. While an orientation of the texture perpendicular to the direction of the cutting force in the turning process leads to a decrease of the critical bending strength of up to $27.1 \%$ for Brazil and Silver quartzite the opposite is true for Alta quartzite. In this case the critical bending strength increases by $25.7 \%$ with a perpendicular orientation of the texture.

Although it can be stated that rocks with an isotropic texture tend to have a higher critical bending strength, in view of the comparably high standard deviation it must be mentioned that the influence of the texture on the critical bending strength could be lower than it appears. Finally, it should be noted, that the described properties are likely to interact with each other and that the full scale of these interactions and their significance could not be covered in this investigation.

\subsection{Grinding of indexable inserts made from rock}

Despite the brittle character of the rocks it is possible to grind them into indexable inserts with comparably smooth surfaces with only few and small brittle outbreaks. It is possible to produce indexable inserts with a chamfered cutting edge and a smooth corner radius $r_{\varepsilon}$ as it can be seen in the SEM-Images shown in Fig. 10. Measurements of the chamfer width show no significant deviation of the intended width of $0.2 \mathrm{~mm}$. The same applies for the corner radius of $0.8 \mathrm{~mm}$.

Surface roughness values on the flank face after grinding are shown in Fig. 11. The arithmetic average roughness
Fig. 10 SEM-images of the surface of the indexable inserts made from rock by a plunge face grinding process
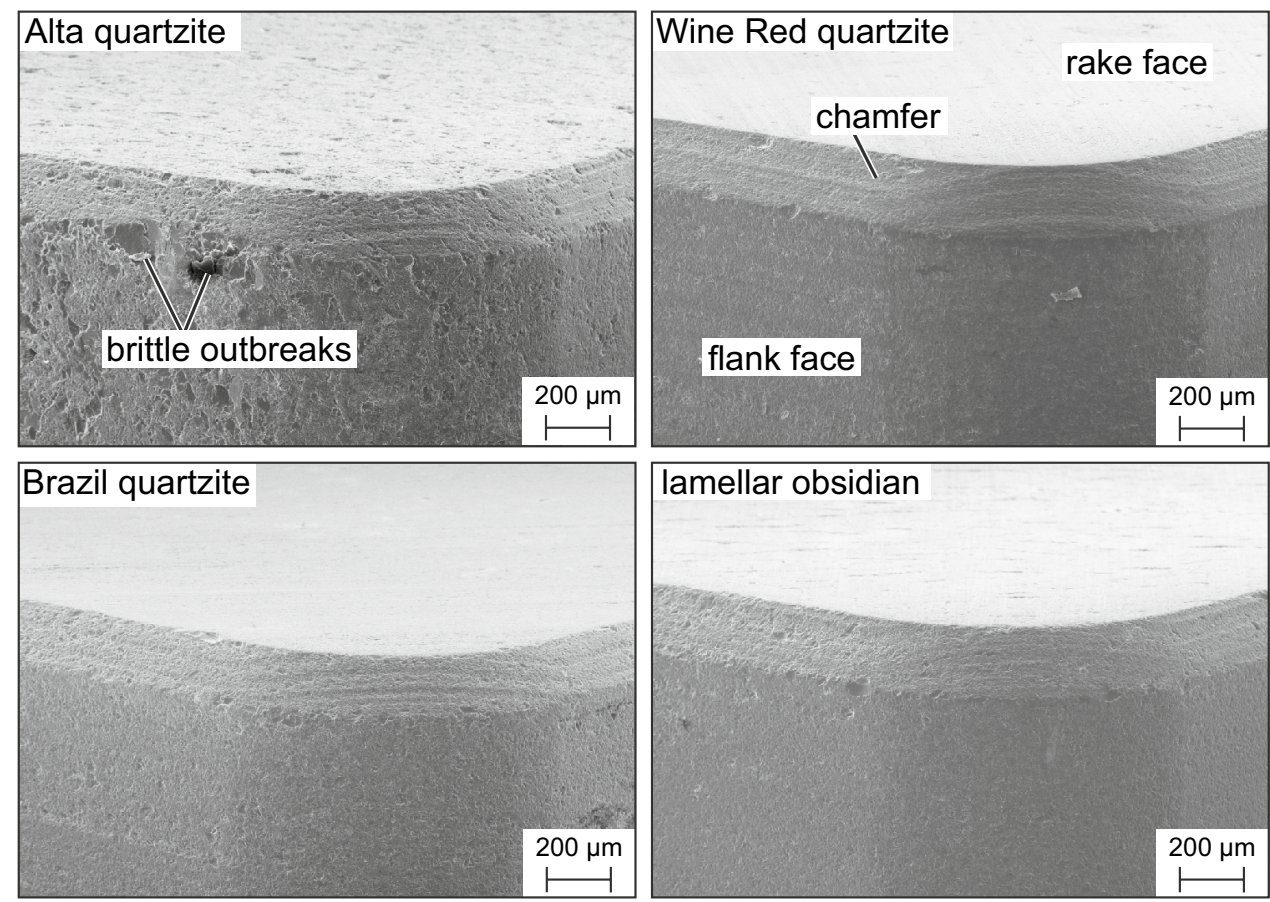
Fig. 11 Surface roughness at the flank face of the inserts after grinding
Fig. 12 Surface roughness of the cutting edge after the grinding process
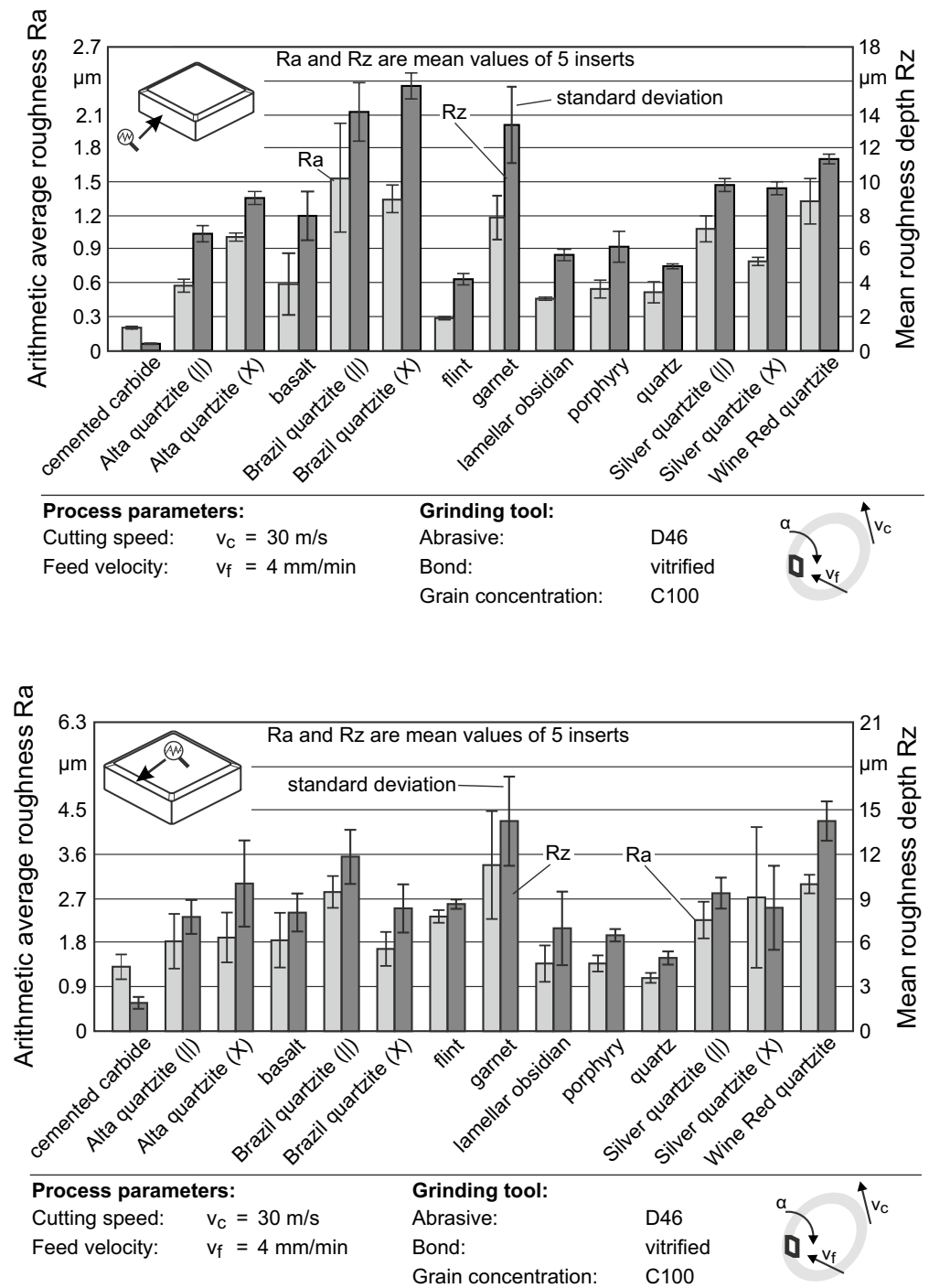

Ra of the ground samples ranges between $0.29 \mu \mathrm{m}$ (flint) and $1.54 \mu \mathrm{m}$ (Brazil quartzite) and the mean roughness depth $\mathrm{Rz}$ of the profile is between $4.26 \mu \mathrm{m}$ (flint) and $15.72 \mu \mathrm{m}$ (Brazil quartzite $(\mathrm{X})$ ). Compared to conventional cemented carbide indexable inserts used as a reference this means a higher surface roughness by a factor of 1.45 to 7.70 in terms of Ra and of 10.65 to 39.3 in terms of Rz. However, it must be remembered that it is not yet known how the grinding process of the rocks should ideally be designed. It is therefore possible that better surface qualities can be achieved as a result of an optimized process design.

The roughness values of the cutting edge are shown in Fig. 12. They range between $1.09 \mu \mathrm{m}$ (quartz) and $3.39 \mu \mathrm{m}$ (garnet) for Ra and between $4.97 \mu \mathrm{m}$ (quartz) and $14.28 \mu \mathrm{m}$ (garnet) for Rz. Compared to the cemented carbide inserts used as a reference in this case, these results show that the roughness of the cutting edge of the rock inserts is either comparable to this reference or higher by a factor of between $2.61(\mathrm{Ra})$ and $7.52(\mathrm{Rz})$.

Furthermore, the cutting-edge geometry of the inserts after grinding was investigated. In order to compare the cutting-edge geometry of the inserts the average cuttingedge rounding $\bar{S}$ is used. $\bar{S}$ describes the dimension of the cutting edge rounding and can be calculated with the following equation using the length of the cutting-edge segment on the flank face $S_{\alpha}$ and the length of the cuttingedge segment on the rake face $S_{\gamma}[40]$ :

$\bar{S}=\frac{S_{\alpha}+S_{\gamma}}{2}$

All rock inserts show an average $\bar{S}$ of $15.0 \pm 5.9 \mu \mathrm{m}$. The average $\bar{S}$ of the cemented carbide inserts is with $17.8 \pm 1.6 \mu \mathrm{m}$ slightly higher. Due to the comparable geometry of the cutting edges of the inserts, it can be 
Fig. 13 Influence of critical bending strength on surface roughness at the flank face
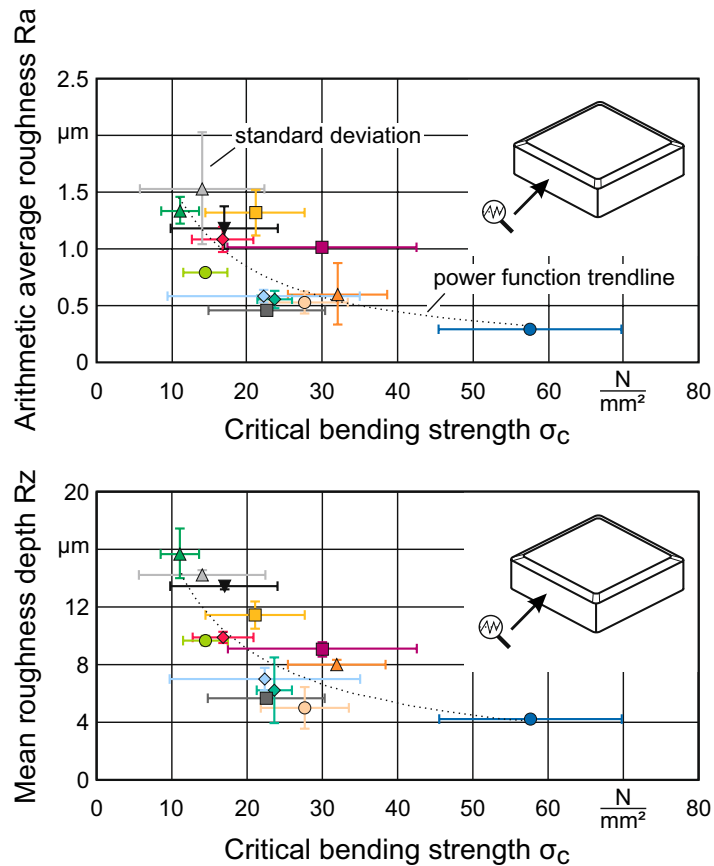

\begin{tabular}{llll}
\hline Process parameters: & Grinding tool: & \\
Cutting speed: & $v_{\mathrm{C}}=30 \mathrm{~m} / \mathrm{s}$ & Abrasive: & B 46 \\
Feed velocity: & $v_{f}=4 \mathrm{~mm} / \mathrm{min}$ & $\begin{array}{l}\text { Bond: } \\
\text { Grain concentration: }\end{array}$ & $\begin{array}{l}\mathrm{C} 100 \\
\end{array}$ \\
& & vitrified
\end{tabular}

assumed that this factor should not influence the operational behaviour of the inserts in different ways.

The results of the surface roughness at the flank face indicate a correlation between texture direction and grinding result. A higher surface roughness is observed when the texture is aligned parallel to the rake face. The only exception to this is Silver quartzite at the flank face, where roughness is comparable for both alignments of the texture. The alignment of the loads in the grinding process relative to the alignment of the texture offers a possible explanation. In case of the samples with a texture alignment parallel to the rake face the tangential force of the grinding process induces shear stress into the mica layers at all flanks of the indexable inserts. This is only the case on two flanks of the indexable inserts when the texture is aligned perpendicular to the rake face. It is possible that the mica layers are more eroded than the surrounding minerals due to their high cleavability as a result of the shear stress caused by the grinding process. This leads to an uneven material removal in these areas and due to this to a higher surface roughness. The findings also show that rocks with a higher critical bending strength tend to show a lower surface roughness after the grinding process as shown in Fig. 13 for the roughness of the flank face. Since higher critical bending strengths indicate higher load bearing capacities of the material it is less likely that larger material agglomerations will be removed from the surface in the grinding process, resulting in a smaller proportion of brittle material removal, a smoother surface and thus a lower surface roughness.

For hardness no uniform influence on surface roughness could be observed although higher hardness is often associated with a higher brittleness of the material which leads to a higher proportion of brittle material removal and due to this to a higher surface roughness. However, it must be mentioned that there are rock samples with a relatively high hardness like the Alta quartzite which show a comparably low surface roughness.

Besides this, it was found that rocks with a high grade of interlocking, especially between the grains and mica textures (e.g., Brazil quartzite), show the highest surface roughness of the investigated samples. This is shown for $\mathrm{Rz}$ in Fig. 14 besides the influence of the crack class. For $R a$ the same tendencies could be observed. The combination of these factors leads to the conclusion that grains or grain agglomerations are broken out of the surface during the grinding process due to an interlocking of the grains, thus reducing surface quality. A higher number of cracks with an orientation that facilitates brittle material removal due to crack propagation and an anisotropic texture are likely reasons for these also negative influences on surface quality. Regarding the anisotropic texture the reason for this is that it facilitates brittle material removal under loads of certain directions. This hypothesis is supported by the fact that for rock samples with a higher crack class and an anisotropic texture the surface roughness tends 
Fig. 14 Influence of interlocking and crack class on surface roughness at flank face after grinding

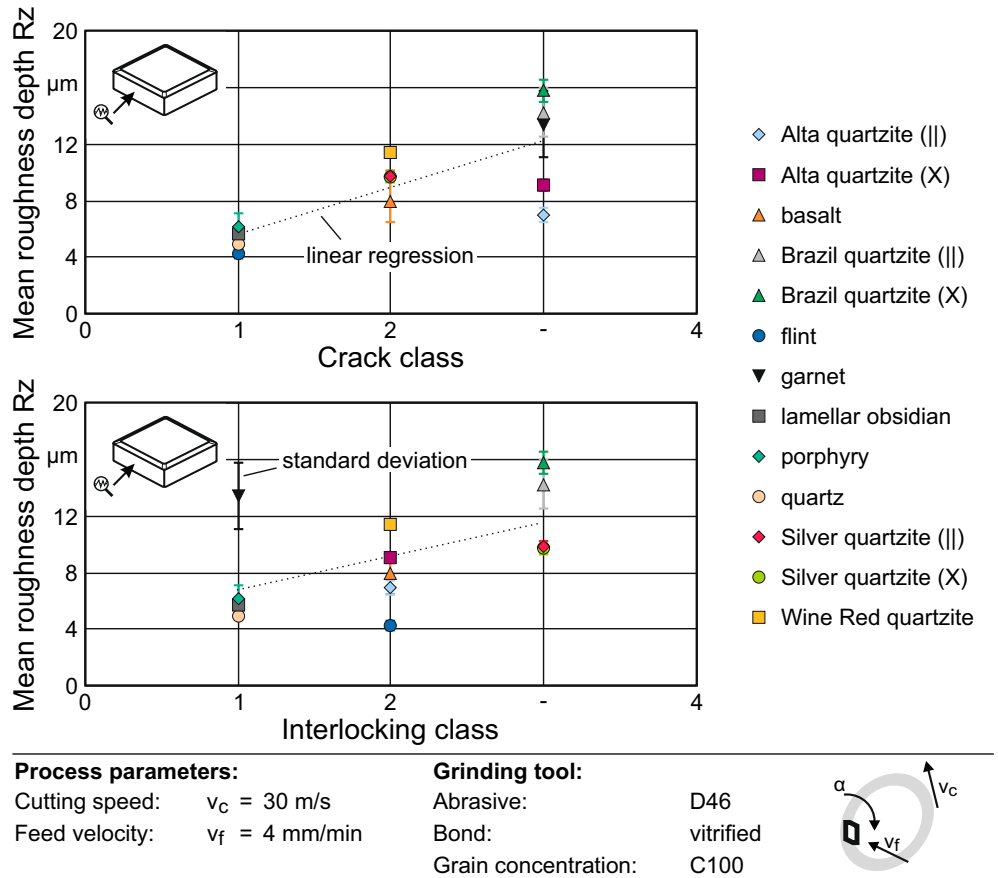

Table 9 Scrap rate after the grinding process

\begin{tabular}{ll}
\hline Rock & $\begin{array}{l}\text { Scrap rate } \\
\text { after grinding } \\
(\%)\end{array}$ \\
\hline Alta quartzite $(\|)$ & 9.1 \\
Alta quartzite $(X)$ & 63.6 \\
basalt & 20.0 \\
Brazil quartzite $(\|)$ & 9.1 \\
Brazil quartzite $(X)$ & 42.9 \\
flint & 0.0 \\
garnet & 33.3 \\
lamellar obsidian & 60.0 \\
porphyry & 0.0 \\
quartz & 20.0 \\
Silver quartzite $(\|)$ & 30.8 \\
Silver quartzite $(X)$ & 42.9 \\
Wine Red quartzite & 10.0 \\
\hline
\end{tabular}

to be higher. Furthermore, this observation is in line with the previous mentioned decrease of the critical bending strength for higher crack and interlocking classes and the observed increase of surface roughness for a decrease of critical bending strength.

A problem in manufacturing of indexable inserts made of rock is a partly high scrap rate after grinding, as shown in Table 9. While rocks like flint or porphyry can be ground without any rejections, other rocks show quite high rates like the Alta quartzite $(X)$ with $63.9 \%$. The results show that an alignment of the texture parallel to the tangential force of the grinding process leads to a higher scrap rate. A possible explanation for this is the before mentioned load of the mica layers.

Crack propagation in the rocks as a result of the loads in the grinding process can also provide an explanation for partly high scrap rates. Not all rocks which showed a high crack density also show a high scrap rate after grinding. Therefore, further factors must also be considered. It is possible that the scrap rate is a result of a suboptimal grinding process. If, for example, the single grain chip thickness is significantly higher than the critical single grain chip thickness, damage to the rock can occur as a result of the brittle material removal, which can lead to a failure of the rock under appropriate loading in the grinding process. Furthermore, it is possible that the oscillation of the grinding wheel in the grinding process leads to a higher scrap rate due to an additional axial load at the indexable inserts.

The application of the rock inserts in the turning of aluminium subsequent to the grinding process show that it is generally possible to machine aluminium with rock inserts. As all inserts are used on a cutting length of $\mathrm{I}_{\mathrm{c}}=500 \mathrm{~m}$, their cutting time at the selected cutting speed of $600 \mathrm{~m} /$ $\min$ is $50 \mathrm{~s}$. However, the wear behaviour of the inserts differs widely between the different rocks. The wear behaviour of the inserts is characterised by abrasive wear on

\subsection{Operational behaviour of indexable inserts made from rocks}




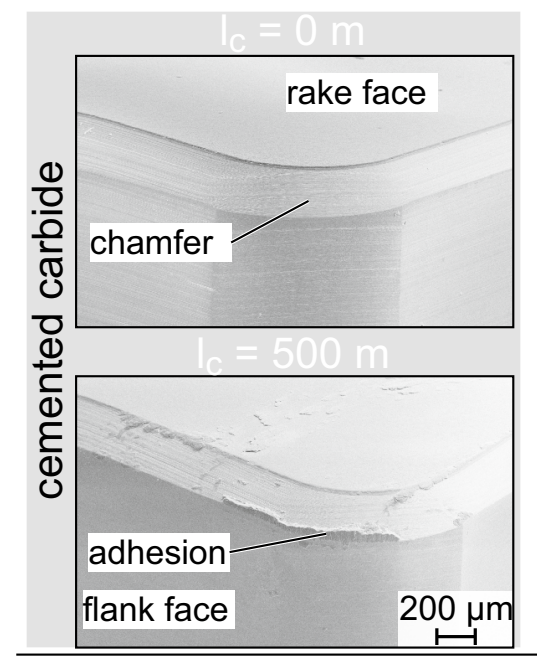

Process parameters:

Cutting speed: $v_{\mathrm{C}}=600 \mathrm{~m} / \mathrm{min}$

Feed:

Depth of cut:

Cutting length:

$$
f=0.1 \mathrm{~mm}
$$

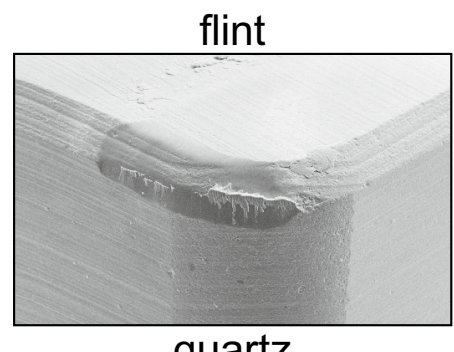

quartz

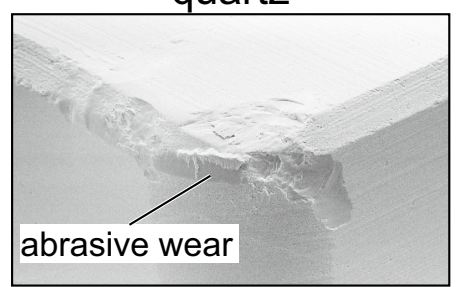

Material:

EN AW 2007 lamellar obsidian
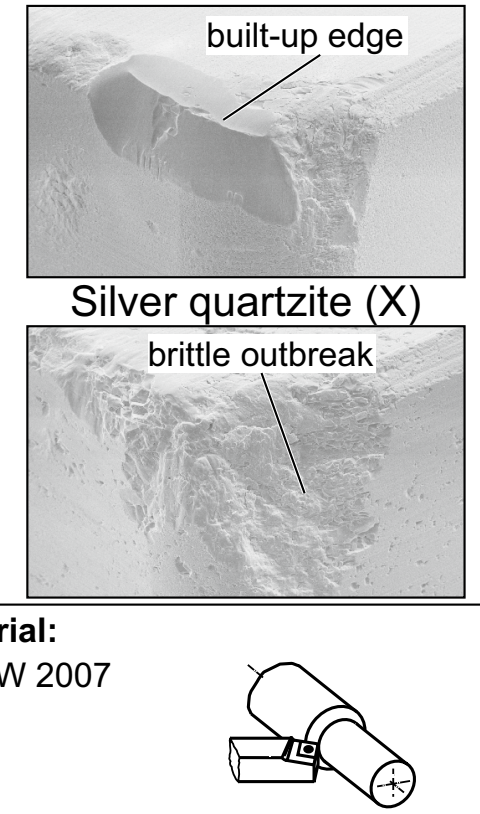

Fig. 15 SEM-images of wear of different rock inserts after turning aluminium compared to a cemented carbide tool
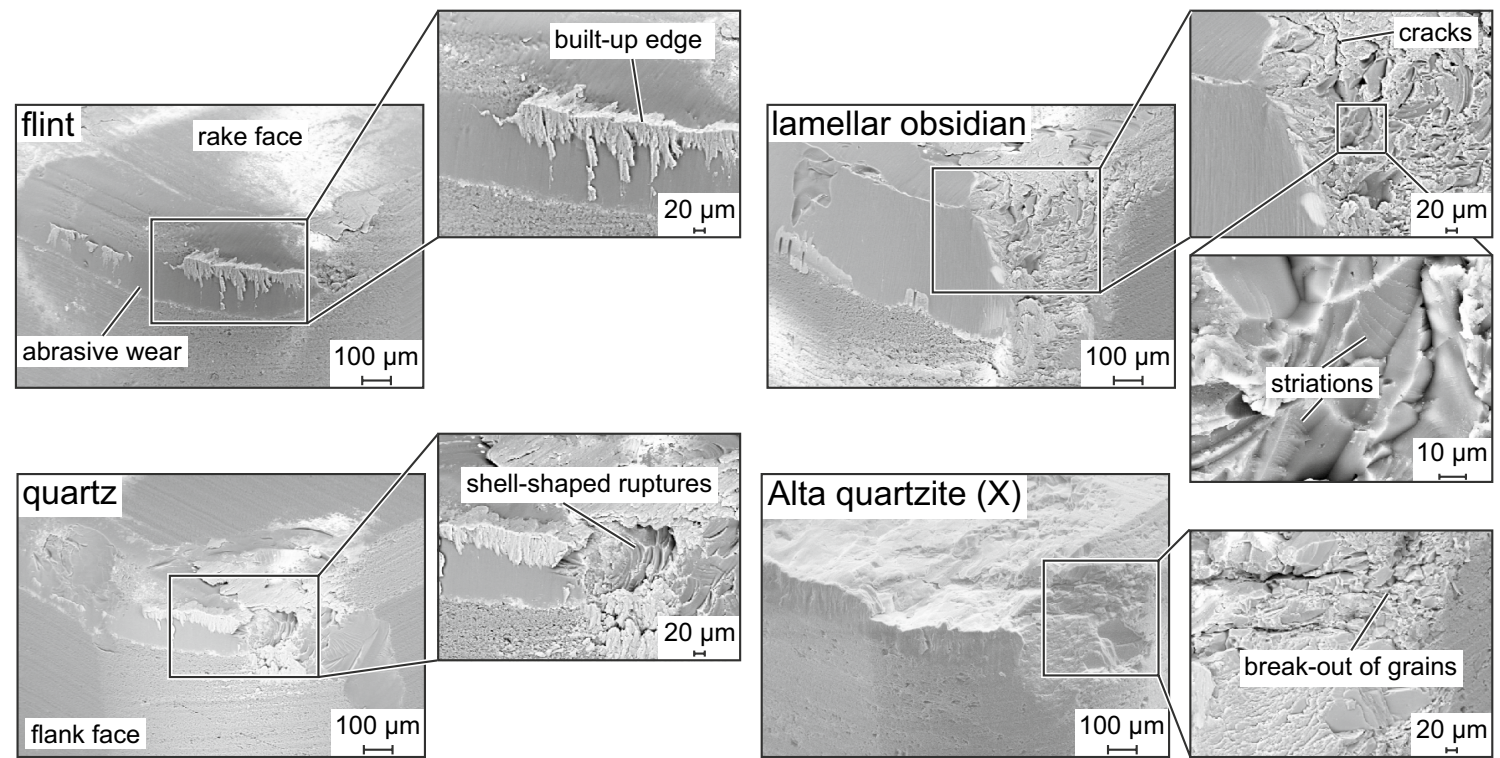

\section{Process parameters:}

Cutting speed:

Feed:

Depth of cut:

Cutting length:
$\mathrm{v}_{\mathrm{C}}=600 \mathrm{~m} / \mathrm{min}$

$$
\mathrm{f}=0.1 \mathrm{~mm}
$$

$a_{p}=0.5 \mathrm{~mm}$

$\mathrm{I}_{\mathrm{C}}=500 \mathrm{~m}$
Material:

EN AW 2007

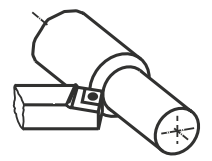

Fig. 16 SEM-images of various wear phenomena that occur after turning of aluminium on rock inserts 
Fig. 17 Width of wear marks at the flank face of the rock inserts for a depth of cut of $0.5 \mathrm{~mm}$

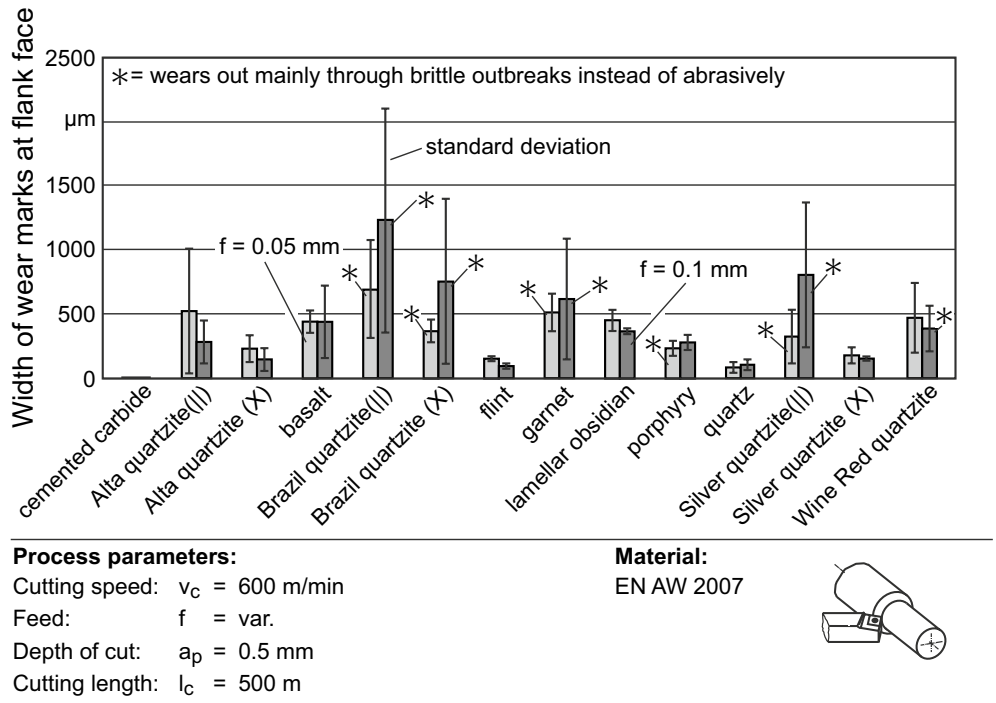

flank and rake face, brittle outbreaks as well as material adhesions as can be seen in Fig. 15 .

The formation of built-up edges is another factor which influences wear of the inserts. A break-out of a built-up edge can for example damage the cuttingedge geometry. The formation and break-out of builtup edges not only influence the wear behaviour, but also the surface quality of the workpiece by changing the cutting-edge geometry. All rocks have a significant higher wear compared to the coated cemented carbide tool which shows only signs of adhesions and low abrasive wear, but neither brittle outbreaks nor cracks (Fig. 15). The occurring wear mechanisms using rock tools are further investigated in Fig. 16 which shows close-ups of the tool wear. The typical fracture types of brittle-hard materials such as the shell-shaped breakouts or the breakout of individual grains are striking. When using lamellar obsidian, even the striations of the amorphous material can be recognised. The fracture forms depend on the rock used, but are due to a mechanical overload of the tool. Accordingly, the machining-related tool load leads to a load that exceeds the mechanical strength and causes the outbreaks.

To describe the different wear behaviour of the inserts the width of the wear marks (brittle and abrasive) at the flank face is used. For this purpose, the width of the worn area on the flank face on each insert was measured at five points. A distinction is made as to whether wear is mainly abrasive or due to outbreaks. The width of wear marks at the flank face of the inserts is shown in Figs. 17 and 18. The marks are between $83 \mu \mathrm{m}$ (quartz) and $1665 \mu \mathrm{m}$ (garnet).
Fig. 18 Width of wear marks at the flank face of the rock inserts for a depth of cut of $1 \mathrm{~mm}$

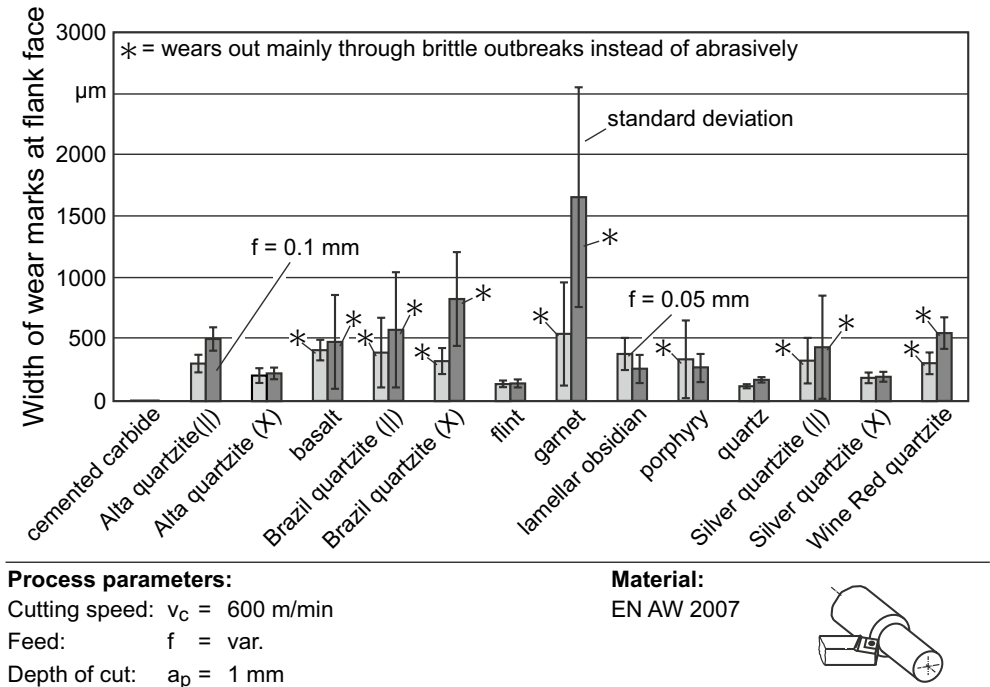

Cutting length: $I_{c}=500 \mathrm{~m}$ 
Fig. 19 Influence of hardness and critical bending strength on wear
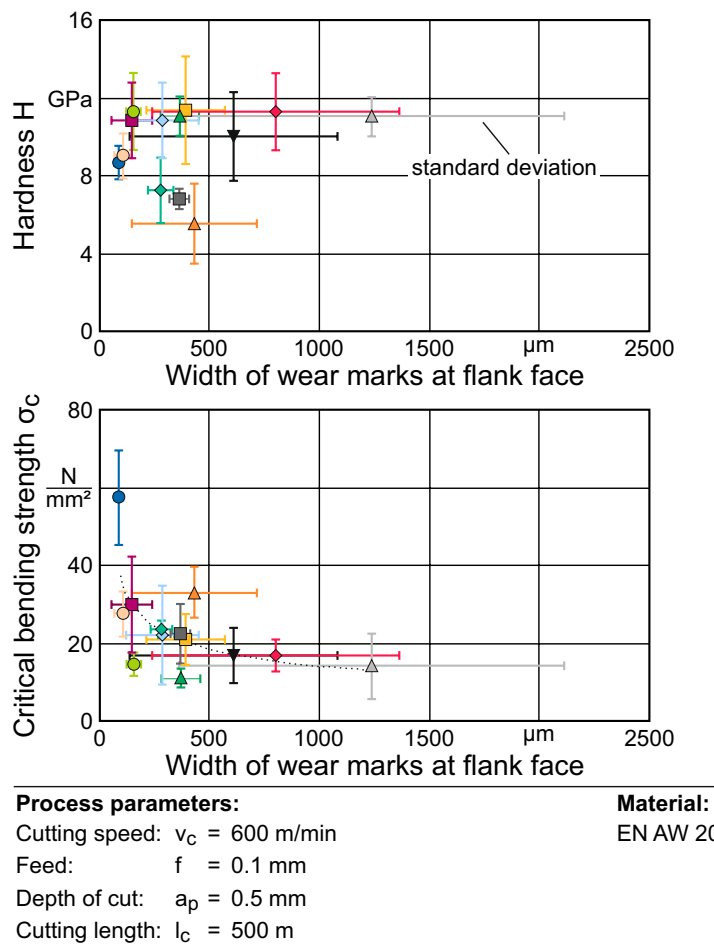

$\diamond$ Alta quartzite $(\|)$

- Alta quartzite $(\mathrm{X})$

$\triangle$ basalt

$\triangle$ Brazil quartzite $(\|)$

$\Delta$ Brazil quartzite $(X)$

- flint

$\checkmark$ garnet

- lamellar obsidian

$\diamond$ porphyry

- quartz

$\diamond$ Silver quartzite (II)

- Silver quartzite (X)

$\square$ Wine Red quartzite
With regard to the influence of the process parameters on wear, no general correlation for all rocks is apparent. While some rocks show higher width of wear marks for higher material removal rates (e.g., garnet), exactly the opposite is the case for other rocks (e.g., lamellar obsidian). However, it can be seen that rocks that have a high width of wear marks also show a high standard deviation due to an increased occurrence of chipping. Thus, when a rock sample reaches a certain degree of wear, the cohesion of the rocks is eased and wear therefore increases, e.g., due to increased crack propagation and shell-shaped breakouts or the breaking out of mineral grains (see Fig. 16).

The results indicate that rocks with a higher critical bending strength tend to show a lower width of wear marks as shown in Fig. 19. Since a higher critical bending strength indicates a higher load-bearing capacity and a better structural cohesion of the microstructure, the lower wear of rocks with high critical bending strengths results from their comparatively better ability to withstand process loads. It can be observed that brittle outbreaks lead in most cases to larger wear marks. Due to the fact that using rocks with higher critical bending strength have mainly abrasive wear, it can be stated that a high critical bending strength promotes abrasive wear and counteracts outbreaks. In contrast, no general influence on the wear behaviour of the inserts can be determined for the hardness (see Fig. 19).

Due to this it is possible to conclude that critical bending strength has a higher influence on the wear behaviour of the rocks in the turning process than their hardness. The reason for this is that hardness of the mixture of minerals which forms the rock is not important as long as it is not able to preserve its structural coherency under load. If grains or grain agglomerations break out of the fabric under load, this leads to wear, which is greater the lower the cohesion of the structure, regardless of the hardness. This hypothesis is supported by the fact that most of those rocks which show higher amounts of wear especially due to outbreaks (e.g., Brazil quartzite, garnet, Silver quartzite) have a comparably low critical bending strength. It can therefore be assumed that the critical bending strength of the rocks is a limiting factor for the usable range of rocks as cutting material.

But as before in the case of the influencing factors relevant to the grinding result, the crack and interlocking class are also relevant for wear. Rocks with higher crack and interlocking classes show a higher amount of wear. With regard to the crack density, this is due to the fact that crack propagation can occur more easily with higher crack density under process loads. This in turn promotes rock failure and thus increases the wear of the inserts. Regarding the interlocking of the grains, it is possible that it supports crack growth and crack initiation under load as mentioned before. However, the fact that crack density and interlocking of the grains also correlate with the critical bending strength must be considered. Therefore, the influence of crack density, interlocking of the grains and critical bending strength cannot be regarded as completely separate. 
Fig. 20 Surface roughness of the workpiece after the turning process

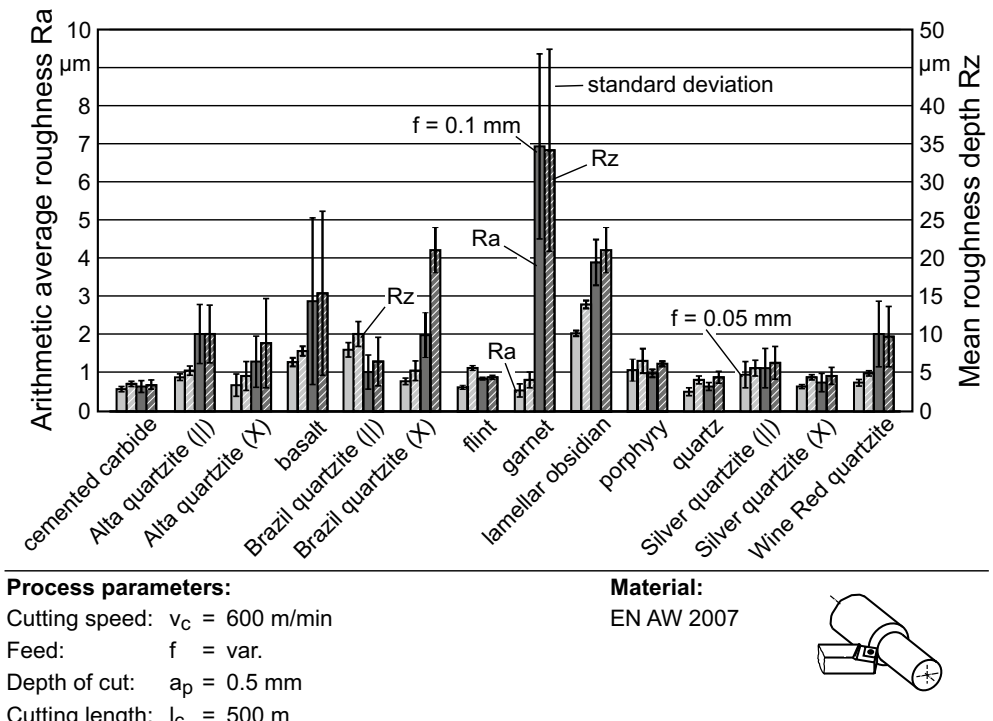

Furthermore, it is also shown that an alignment of existing textures in the rock orthogonal to the cutting force during turning can lead to a significant reduction of the width of wear marks of up to $77.5 \%$. A possible explanation for this is that if the textures are aligned perpendicular to the cutting force, the different layers of the rock are only subjected to a compressive load by the cutting force. Since rocks can generally withstand compressive loads better than tensile or shear loads, damage to the rock as a result of the stress caused by the turning process occurs less frequently and therefore also less wear.

For a manufacturing process not only tool wear but also the achievable workpiece quality is important. To evaluate the workpiece quality after turning with indexable inserts made of rocks the surface quality of the workpiece is used. The resulting surface roughness after the turning experiments is shown in Fig. 20 for a depth of cut of $0.5 \mathrm{~mm}$. Compared to the surface roughness achieved with the cemented carbide inserts it can be seen that it is possible to achieve a similar surface roughness by using rock inserts. However, it also becomes clear that this does not apply to all rocks examined. The high standard deviation of the surface roughness of some rocks is a consequence of the high variation in tool wear. Above, the deviation was deduced as a consequence of exceeding the critical bending strength and confirmed with the higher incidence of brittle outbreaks. This in turn leads to a direct change in the cutting-edge geometry and thus to a deterioration of the surface roughness. The formation of built-up edges also contributes to this as mentioned before. Furthermore, it was found that rocks with higher critical bending strengths tend to generate a lower surface roughness in the turning process which is in line with the previously mentioned correlation between wear and critical bending strength. Besides that, it can be seen, that an alignment of mica layers perpendicular to the cutting force in the turning process can lead to a reduction of surface roughness.

The results of this investigation show that the choice of rock for use as cutting tool material plays a major role in the manufacturing process and the operational behaviour of indexable inserts made of rock. Considering wear behaviour and achieved surface roughness after the turning process flint, quartz, Alta quartzite as well as Silver quartzite with a texture orientation perpendicular to the cutting force in the turning process achieved the best results. For this reason, chip formation and process forces during machining are finally analysed for these four rocks as well as lamellar obsidian. Figure 21 shows the cutting and feed forces of the rock inserts as well as the carbide tool in the diagram. Microscope images of the chips produced are shown on the right. The diagram shows the mean value of two force measurements over a cutting length of $200 \mathrm{~m}$ as well as the corresponding standard deviation. The force measurements show an increase in the average force of a minimum of $5 \%$ (flint) to a maximum of $20 \%$ (lamellar obsidian) in relation to the reference tool (cemented carbide). In addition, cemented carbide shows almost no standard deviation; this is due to the low wear of the tool over the cutting length and the resulting low influence on the process forces. The wear behaviour of the rocks used is also reflected in the process forces. With the exception of lamellar obsidian, the mean values are only slightly higher than those of cemented carbide. However, the deviation that occurred is significantly higher and can be explained by the increase in wear during the force measurement. The significantly higher forces in the case of lamellar obsidian can be explained by the built-up edges visible in Fig. 15 or the higher surface roughness of the 

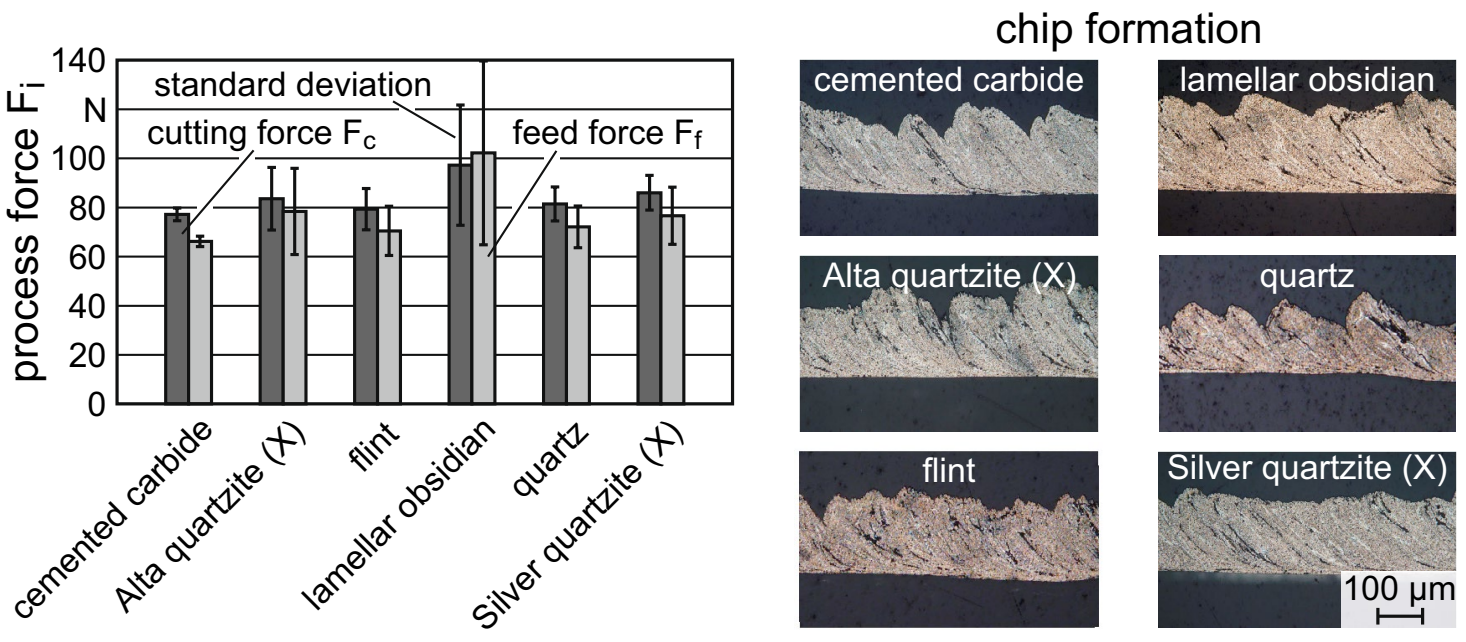

\begin{tabular}{ll}
\hline Process parameters: \\
Cutting speed: & $v_{c}=600 \mathrm{~m} / \mathrm{min}$ \\
Feed: & $f=0.1 \mathrm{~mm}$ \\
Depth of cut: & $a_{p}=0.5 \mathrm{~mm}$ \\
Cutting length: & $\mathrm{I}_{\mathrm{c}}=200 \mathrm{~m}$
\end{tabular}

Material:

EN AW 2007

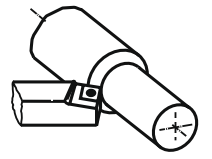

Fig. 21 Process forces and chip formation using rock inserts by machining aluminium

workpiece in Fig. 20. The high material adhesion, probably due to chemical processes between workpiece and cutting material, significantly changes the cutting wedge geometry and results in a change in the acting forces. In general, the investigation shows a marginal influence on chip formation when using rock tools. The comparable chip shapes indicate comparable contact lengths on the tool and temperatures in the effective zone. Only the low degree of segmentation in flint and Silver quartzite could indicate different tribological mechanisms. The causes could be different chip surface roughness or chemical processes with the material.

After considering process forces and chip formation, the suitability of flint, quartz, Alta and Silver quartzite as an alternative cutting material is confirmed. However, it must also be taken into account that these quartzites have a comparatively high reject rate after grinding, which affects their suitability as a cutting material until the grinding process can be improved. These rocks also show that an unfavourable orientation of the textures in the rock to the load direction can also have a negative influence on the suitability of the rock as a cutting material. For future evaluations of the suitability of rocks as cutting materials compared to other rocks, it is recommended to use quartz as a reference material as it is a comparatively pure mineral, which means that its mechanical properties should not show intense variations. Furthermore, quartz is one of the most common minerals and can be technically produced in high purity. This makes quartz a readily available reference of high quality. In addition, quartz showed good operating behaviour as a cutting material compared to the other rocks. Even though the rock tools have so far only been investigated for machining EN AW 2007-T4, it should also be possible to machine materials with a lower strength, such as plastic, with the rocks. For the machining of harder materials, further investigations need to be carried out.

Future research projects should further investigate the fundamentals of tool grinding of rock tools and the operational behaviour of rock tools in order to better understand and improve them and to enable an industrial use of cutting tools made of rocks. Concerning the investigation of the tool grinding process it would be beneficial to enhance the understanding of the process by knowing the occurring material removal mechanisms and critical single grain chip thicknesses of rocks suitable for the use as cutting materials in correlation with their properties. Furthermore, it would be advantageous to know the optimum process parameters of the grinding process and the roughness of the tools that can be achieved as a function of these parameters, as well as their scattering width. This would enable highly productive tool grinding processes for the manufacture of rock tools with a high quality and low rejection rates and prevent grinding related damages to the tools. With regard to operational behaviour, a better understanding of the influence of the tool geometry and process parameters during turning could improve operational behaviour and enable an industrial use of rock 
tools. For this purpose, investigations on the influence of the cutting edge geometry and the tool angles used on process loads, wear and surface qualities achieved as well as investigations on optimised tool design in correlation with the rock properties and optimal parameters for the turning process when using rock tools are necessary.

\section{Conclusions}

This paper investigates the suitability of different rocks for the use as cutting material. The rock properties are investigated by using thin sections, hardness measurements and three-point bending tests. Indexable inserts are made of the rocks via a grinding process and applied in the turning of aluminium. The surface roughness of the inserts, the workpiece as well as the wear of the inserts are measured and used to analyse the suitability of the rocks as cutting material. Based on the obtained results the following conclusions can be drawn:

- Rocks can be used as an alternative cutting material compared to carbide as indexable inserts, thus reducing the natural resources required

- The bending strength of the rocks can be used as a selection criterion for their suitability as a cutting material

- Flint, quartz and Alta quartzite as well as Silver quartzite with a texture orientation perpendicular to the cutting force in the turning process are the most suitable for the use as cutting tool material of the investigated rocks

- The cutting tests show a similar chip formation with suitable rocks compared to coated cemented carbide tools. However, tool wear is significantly higher and does not allow industrial use yet

- The further adaptation of the grinding of rocks as well as an optimisation of the tool geometry and process parameters offer research and development potential to establish rocks as an industrial cutting material

Acknowledgements The authors would like to thank the German Research Foundation (DFG) for supporting the project BR 2967/12-1 "Manufacturing and operational behaviour of cutting tools made of rock". The technical support of the Institute of Mineralogy of the Leibniz University Hannover and the Institute of Materials Engineering of the Technische Universität Dortmund is gratefully acknowledged.

Authors' contribution B. Bergmann developed the concept of the work. B. Breidenstein was responsible for funding acquisition, project administration and supervision. He also reviewed and edited the manuscript in the writing process together with B. Denkena, A. Krödel and T. Picker. P. Wolters conducted the experiments together with T. Picker and analysed the data. P. Wolters wrote the manuscript.
Funding Open Access funding enabled and organized by Projekt DEAL. This work was supported by the German Research Foundation (DFG) under grant number BR 2967/12-1.

\section{Declarations}

Conflict of interest On behalf of all authors, the corresponding author states that there is no conflict of interest.

Open Access This article is licensed under a Creative Commons Attribution 4.0 International License, which permits use, sharing, adaptation, distribution and reproduction in any medium or format, as long as you give appropriate credit to the original author(s) and the source, provide a link to the Creative Commons licence, and indicate if changes were made. The images or other third party material in this article are included in the article's Creative Commons licence, unless indicated otherwise in a credit line to the material. If material is not included in the article's Creative Commons licence and your intended use is not permitted by statutory regulation or exceeds the permitted use, you will need to obtain permission directly from the copyright holder. To view a copy of this licence, visit http://creativecommons. org/licenses/by/4.0/.

\section{References}

1. Furberg A, Arvidsson R, Molander S (2019) Enviromental life cycle assessment of cemented carbide (WC-Co) production. J Clean Prod 209:1126-1138

2. Werner ABT, Sinclair WD, Amey EB (2014) International strategic mineral issues summary report - Tungsten (Ver. 1.1, November 2014): U.S. Geological Survey Circular 930-O. U.S. Department of the Interior, Reston, VA

3. European Commission (2017) Communication from the commission to the European parliament, the council, the European economic and social committee and the committee of the regions on the 2017 list of critical raw materials for the EU; Brussels

4. European Commission (2018) Report on Critical Raw Materials and the Circular Economy; Brussels

5. European Union Project (2017) Flintstone 2020 Next generation of superhard non-CRM materials and solutions in tooling - Project Fact Sheet. Lunds Universitet, Lund

6. Hrechuk A, Johansson D, Bushlya V, Devin L, Ståhl J-E (2018) Application of Colding tool life equation on the drilling fiber reinforcement polymers. Procedia Manuf 25:302-308

7. Klocke F (2011) Manufacturing processes 1: cutting. Springer, Berlin

8. Toenshoff HK, Denkena B (2013) Basics of cutting and abrasive processes. Springer, Berlin

9. Wittke W (1990) Rock mechanics - theory and applications with case histories. Springer-Verlag, Berlin Heidelberg

10. Johansson $E$ (2011) Technological properties of rock aggregates. Doctoral Thesis, Luleå University of Technology

11. Brookes K (1987) World directory and handbook of hardmetals. International Carbide Data, St. Albans Hearts

12. Kalyan B, Murthy ChSN, Choudhary RP (2015) Rock indentation indices as criteria in rock excavation technology - a critical review. Procedia Earth Planet Sci 11:149-158

13. Altindag R, Güney A (2006) ISRM suggested method for determining the shore hardness value for rock. Int J Rock Mech Min Sci 43:19-22 
14. Ulusay R, Hudson JA (eds) (2007) The complete ISRM suggested methods for rock characterization, testing and monitoring: 1974-2006. International Society for Rock Mechanics, Lisbon

15. Meng F, Wong LNY, Zhou H (2021) Rock brittleness indices and their applications to different fields of rock engineering: a review. J Rock Mech Geotech Eng 13:221-247

16. Nishimatsu Y (1972) The mechanics of rock cutting. Int J Rock Mech Min Sci Geomech Abstr 9(2):261-270

17. Sarışık G, Özkan E (2018) Effects of natural rock properties on cutting forces, specific energy and specific cutting energy by four-axis machine. Arab J Geosci 11:84

18. Sarışık G (2021) Investigation on cutting parameter models and processability index in 3D marble products with milled tools. Arab J Geosci 14:1854

19. Garner NE (1967) Cutting action of a single diamond under simulated borehole conditions. J Petrol Technol 19:937-942

20. Wang CY, Clausen R (2002) Marble cutting with single point cutting tool and diamond segments. Int J Mach Tools Manuf 42(9):1045-1054

21. Huang H, Lecampion B, Detournay E (2013) Discrete element modelling of tool-rock interaction I: rock cutting. Int J Numer Anal Meth Geomech 37:1913-1929

22. Mohammadnejad M, Dehkhoda S, Fukuda D, Liu H, Chan A (2020) GPGPU-parallelised hybrid finite-discrete element modelling of rock chipping and fragmentation process in mechanical cutting. J Rock Mech Geotech Eng 12:310-325

23. McQueen LB, Purwodihardjo A, Barrett SVL (2019) Rock mechanics for design of Brisbane tunnels and implications of recent thinking in relation to rock mass strength. J Rock Mech Geotech Eng 11:676-683

24. Zhang Y-Q, Hao H, Lu Y (2003) Anisotropic dynamic damage and fragmentation of rock materials under explosive loading. Int $J$ Eng Sci 41:917-929

25. Denkena B, Boehnke D, Bockhorst J (2009) Thin tools for the high speed cutting of granite. Int J Abras Technol 2(2):173-183

26. Turchetta S, Sorrentino L (2019) Forces and wear in high-speed machining of granite by circular sawing. Diam Relat Mater 100:107579

27. Dormishi A, Ataei M, Mikaeil R, Khalokakaei R, Haghshenas SS (2019) Evaluation of Gang saws' performance in the carbonate rock cutting process using feasibility of intelligent approaches. Eng Sci Technol Int J 22:990-1000

28. Almasi SN, Bagherpour R, Mikaeil R, Ozcelik Y (2017) Analysis of bead wear in diamond wire sawing considering the rock properties and production rate. Bull Eng Geol Environ 76:1593-1607
29. Özkan E, Öz O (2021) The effect of characterization of carbide end milled limestones on optimal parameters. Arab J Geosci 14:1181

30. Polini W, Turchetta A (2004) Force and specific energy in stone cutting by diamond mill. Int J Mach Tools Manuf 44:1189-1196

31. Rietveld HM (1969) A profile refinement method for nuclear and magnetic structures. J Appl Crystallogr 2(2):65-71

32. Deutsches Institut für Normung (2018) Metallic materials vickers hardness test - Part 2: verification and calibration of testing machines (ISO 6507-2:2018); German version EN ISO 6507-2:2018; DIN Deutsches Institut für Normung e.V., Berlin

33. Deutsches Institut für Normung (2005) Advanced technical ceramics - mechanical properties of monolithic ceramics at room temperature - Part 4: vickers, Knoop and Rockwell superficial hardness; German version EN 843-4: 2005; DIN Deutsches Insitut für Normung e.V., Berlin

34. Deutsches Institut für Normung (2008) Advanced technical ceramics - mechanical properties of monolithic ceramics at room temperature - Part 1: determination of flexural strength. German version EN 843-1:2006; DIN Deutsches Institut für Normung e.V., Berlin

35. Deutsches Institut für Normung: Aluminium and aluminium alloys - Chemical composition and form of wrought products - Part 3: Chemical composition and form of products; German version EN 573-3:2019; DIN Deutsches Institut für Normung e.V. (2019), Berlin

36. Callister WD, Rethwisch DG (2013) Fundamentals of materials science and engineering, 4th edn. Wiley, Hoboken, N.J.

37. O'Quigley DGF, Luyckx S, James MN (1997) An empirical ranking of a wide range of WC-Co grades in terms of their abrasion resistance measured by the ASTM standard B 611-85 test. Int J Refract Metal Hard Mater 15:73-79

38. Gouldstone A, Chollacoop N, Dao M, Li J, Minor AM, Shen Y-L (2007) Indentation across size scales and disciplines: recent developments in experimentation and modelling. Acta Mater 55:4015-4039

39. Denkena B, Grove T, Bremer I, Behrens L (2016) Design of bronzebonded grinding wheel properties. CIRP Ann Manuf Technol 65:333-336

40. Denkena B, Biermann D (2014) Cutting edge geometries. CIRP Ann Manuf Technol 63:631-653

Publisher's Note Springer Nature remains neutral with regard to jurisdictional claims in published maps and institutional affiliations. 